Keilla Lopes Castilho Jachelli

\title{
Lemas de Sperner e Aplicações
}

Dissertação de Mestrado

Dissertação apresentada como requisito parcial para obtenção do grau de Mestre pelo Programa de Pós-graduação em Matemática do Departamento de Matemática do Centro Técnico Científico da PUC-Rio.

Orientador: Prof. Alessandro Gaio Chimenton 


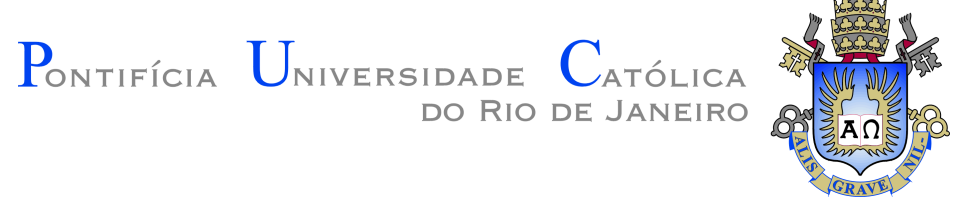

Keilla Lopes Castilho Jachelli

\section{Lemas de Sperner e Aplicações}

Dissertação apresentada como requisito parcial para obtenção do grau de Mestre pelo Programa de Pós-graduação em Matemática do Departamento de Matemática do Centro Técnico Científico da PUC-Rio. Aprovada pela Comissão Examinadora abaixo assinada.

Prof. Alessandro Gaio Chimenton

Orientador

Departamento de Matemática - PUC-Rio

Prof. José Victor Goulart Nascimento

Departamento de Matemática - PUC-Rio

Prof. João Antonio Recio da Paixão

Instituto de Matemática - UFRJ

Prof. Fábio Luiz Borges Simas

Departamento de Matemática - UNIRIO

Prof. Márcio da Silveira Carvalho

Coordenador Setorial do Centro Técnico Científico - PUC-Rio

Rio de Janeiro, 04 de Setembro de 2017 
Todos os direitos reservados. É proibida a reprodução total ou parcial do trabalho sem autorização da universidade, do autor e do orientador.

\section{Keilla Lopes Castilho Jachelli}

Graduou-se em Licenciatura em Matemática pelo CEFET de Campos dos Goytacazes, RJ, (atual IFF-Campos) em 2007. Tem pós-guaduação em Fundamentos de Matemática Elementar em 2011 pela Universidade Salgado de Oliveira, na mesma cidade.

Ficha Catalográfica

Jachelli, Keilla Lopes Castilho

Lemas de Sperner e Aplicações / Keilla Lopes Castilho Jachelli; orientador: Alessandro Gaio Chimenton . - Rio de janeiro: PUC-Rio, Departamento de Matemática , 2017.

v., 45 f: il. color. ; $30 \mathrm{~cm}$

Dissertação (mestrado) - Pontifícia Universidade Católica do Rio de Janeiro, Departamento de Matemática .

Inclui bibliografia

1. Matemática - Teses. 2. Demonstrações - Teses. 3. Lemas de Sperner;. 4. Teorema de Monsky;. 5. Teorema do ponto fixo de Brouwer; . 6. Jogos no ensino de Matemática. I. Chimenton, Alessandro Gaio. II. Pontifícia Universidade Católica do Rio de Janeiro. Departamento de Matemática . III. Título. 
Dedico este trabalho à minha mãe, Maria Helena Lopes Castilho, que não teve muita oportunidade de estudar, mas sempre teve a sabedoria necessária para me educar, apoiar, incentivar e não me deixar desistir. Te amo, mãe! 


\section{Agradecimentos}

Aos meus pais, Maria Helena Lopes Castilho e Amaro Castilho Filho, pelo amor, cuidado, apoio e incentivo, por sempre me oferecerem condições e oportunidade de estudar.

Aos meus irmãos e sobrinhos, pela preocupação, cuidado, amor, torcida e compreensão da minha ausência.

Ao querido amigo, Victor Jachelli, por seu amor, cuidado, apoio, preocupação e incentivo. Por se dispor a me ouvir e discutir matemática, mesmo não sendo sua área e, principalmente, por acreditar na minha capacidade, quando eu mesma não acreditei e por não me deixar desistir nas horas difíceis.

À Rosali Jachelli e Walter Tavares pelo amor, cuidado e ajuda durante grande parte da minha vida acadêmica.

À amiga e vizinha Gilka do Nascimento pelas palavras e orações.

À tia Célia (Marlicea Castilho) pelo acolhimento em sua casa.

Aos amigos do Profmat-UENF-2012, onde essa história começou. Em especial, as amigas de estudo Sandra Maia, Vanessa Barcelos e a saudosa Elza Prado, exemplo de força, coragem e determinação.

Aos amigos de estudo, Vanessa, Larissa e Felipe por todo conhecimento, momentos bons e difíceis que compartilhamos e superamos. E aos demais colegas da turma que de alguma forma contribuíram para meu crescimento.

Aos companheiros de estudo e estrada, Waldeir e Sérgio, por tornarem cada quilômetro precorrido mais divertido e em oportunidade de aprendizagem.

Aos amigos do trabalho e da vida por estarem presentes nos bons e maus momentos dessa caminhada, pelo carinho e incentivo.

À Luciana Cavalcanti pela ajuda com a tradução, a Marcos Machado pelos esclarecimentos de regras da Língua Portuguesa e à Tatiana Quintana por me acompanhar para fazer a matrícula do curso.

Ao programa PROFMAT e a PUC-Rio, pela oportunidade dessa especialização e a CAPES pela ajuda financeira.

A todos os professores que fizeram parte da minha formação, destacando os professores que atuaram nesse curso. 
Ao professor Otavio Kaminski, pelas belíssimas figuras.

Aos alunos que participaram desse estudo, pelo comprometimento e interesse em aprender matemática.

Por fim, deixo um agradecimento especial ao meu orientador, Alessandro, por tornar possível a realização desse trabalho, por sua dedicação e parceria, pelas muitas horas de estudo e conhecimentos compartilhados e, principalmente, pelo seu contagiante entusiasmo em discutir, ensinar e aprender matemática. 


\section{Resumo}

Jachelli, Keilla Lopes Castilho; Chimenton, Alessandro Gaio. Lemas de Sperner e Aplicações. Rio de Janeiro, 2017. 45p. Dissertação de Mestrado - Departamento de Matemática , Pontifícia Universidade Católica do Rio de Janeiro.

Esse trabalho visa demonstrar os lemas de Sperner e aplicá-los nas demonstrações do teorema de Monsky em $\mathbb{Q}^{2}$ e do teorema do ponto fixo de Brouwer em $\mathbb{R}^{2}$. Além disso, relatamos como esses lemas foram abordados com alunos da educação básica tendo como ferramenta educacional jogos de tabuleiro.

\section{Palavras-chave}

Lemas de Sperner; Teorema de Monsky; Teorema do ponto fixo de Brouwer; Jogos no ensino de Matemática. 


\section{Abstract}

Jachelli, Keilla Lopes Castilho; Chimenton, Alessandro Gaio (Advisor). Sperner's lemmas and applications. Rio de Janeiro, 2017. 45p. Dissertação de mestrado - Departamento de Matemática , Pontifícia Universidade Católica do Rio de Janeiro.

This work aims to prove the Sperner's Lemmas and to apply them in proving the Monsky's Theorem in $\mathbb{Q}^{2}$ and the Brouwer fixed point Theorem in $\mathbb{R}^{2}$. Moreover, we report how these lemmas were addressed with students in basic education using board games as educational tools.

\section{Keywords}

Sperner's Lemmas; Monsky's Theorem; Brouwer fixed point Theorem; Games in teaching mathematics. 


\section{Sumário}

1 Introdução $\quad 12$

2 Lema de Sperner para segmentos $\quad 14$

2.1 Lema de Sperner $\quad 14$

2.2 Jogo dos Impactos $\quad 15$

$\begin{array}{ll}2.3 \text { Valorações Diádicas } & 17\end{array}$

2.4 Uma coloração notável de $\mathbb{Q}^{2} \quad 18$

2.5 O teorema de Monsky 22

3 Lema de Sperner para triangulações $\quad 26$

3.1 Lema de Sperner 26

3.2 O Jogo de Sperner 29

3.3 Teorema do ponto fixo de Brouwer para um triângulo em $\mathbb{R}^{2} \quad 31$

4 Aplicações no ensino $\quad 33$

4.1 Jogo dos Impactos 33

$\begin{array}{ll}4.2 \text { Jogo de Sperner } & 37\end{array}$

5 Considerações finais $\quad 40$

$\begin{array}{ll}\text { Referências bibliográficas } & 41\end{array}$

A Prova do Lema 2.8 42

B Prova do Lema $2.10 \quad 44$ 


\section{Lista de figuras}

Figura 1.1 Um segmento com 7 subsegmentos "azuis-vermelhos". 12

Figura 2.1 Um segmento "12". 14

Figura 2.2 Um tabuleiro com $n=10$ casas. 15

Figura 2.3 Jogo ainda não terminado. Jogador $\mathcal{A}$ (vermelho) começou. 16

Figura 2.4 Jogo concluído, com vitória do Jogador $\mathcal{A}$. 16

Figura 2.5 Coloração de $84 \times 83$ pontos em $[0,1] \times[0,1] . \quad 19$

Figura 2.6 Coloração de $51 \times 51$ pontos em $\left[0, \frac{355}{339}\right] \times\left[0, \frac{355}{339}\right] . \quad 20$

Figura 2.7 Um triângulo completo. 20

Figura 2.8 Translação de um triângulo. 21

Figura 2.9 Vértices da mesma cor. 23

Figura 2.10 Vértices de duas cores. 23

Figura 2.11 Triângulo completo. $\quad 24$

Figura 3.1 Uma triangulação e uma não-triangulação do heptágono regular. $\quad 26$

Figura 3.2 Uma triangulação de $P$ com 7 triângulos completos e 5 arestas " 12 " nos lados de $P$. 27

Figura 3.3 Uma triangulação de $P$ e pontos auxiliares para contagem. 27

Figura 3.4 Triangulação sem triângulos completos. 29

$\begin{array}{lll}\text { Figura 3.5 Um tabuleiro com } 6 \text { arestas em cada lado. } & 29\end{array}$

Figura 3.6 Um jogo encerrado. 30

Figura 3.7 Esquema de coloração aplicado aos vértices de $\mathbb{T}$. 31

Figura 3.8 Triangulações de $\mathbb{T}$ para $n=2, n=3$ e $n=4$ respectivamente.

Figura 4.1 Jogo terminado. Os números indicam o jogador que venceu. 34

Figura 4.2 Jogo dos Impactos no círculo. O segundo jogador é azul e ganhou. $\quad 35$

Figura 4.3 Jogo dos Impactos no círculo. 36

$\begin{array}{ll}\text { Figura 4.4 Uma "coroa circular". } & 37\end{array}$

$\begin{array}{lll}\text { Figura 4.5 } & \text { O Lema de Sperner para triangulações. } & 38\end{array}$

Figura 4.6 O Jogo de Sperner. 38

Figura 4.7 Jogo de Sperner adaptado. 39 
"Não é sobre chegar no topo do mundo E saber que venceu

É sobre escalar e sentir Que o caminho te fortaleceu."

Vilela, Ana. 


\section{Introdução}

Neste trabalho estudamos algumas consequências geométricas, combinatórias e analíticas dos Lemas de Sperner, e algumas aplicações dos mesmos no ensino. O mais simples de tais lemas afirma que um segmento com extremos de cores vermelha e azul e finitos pontos interiores marcados com essas cores deve ter um número ímpar de subsegmentos de extremos coloridos com vermelho e azul (Figura 1.1). A demonstração deste resultado é elementar, mas suas consequências podem ser profundas.

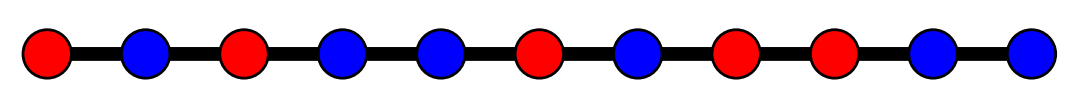

Figura 1.1: Um segmento com 7 subsegmentos "azuis-vermelhos".

Em 1928, Emanuel Sperner encontrou uma prova surpreendentemente simples do teorema do ponto fixo de Brouwer, baseada em um argumento combinatório (1). As ferramentas que Sperner desenvolveu para obter tal prova têm consequências surpreendentes e são fonte de pesquisa nos dias atuais por exemplo em computação (2). Nesta dissertação provaremos duas versões de tais lemas. No Capítulo 2 trataremos do lema de Sperner para segmentos e no Capítulo 3 exporemos o caso de triangulações de polígonos. Como aplicação, no Capítulo 2 provaremos o teorema de Monsky e no Capítulo 3 provaremos o teorema do ponto fixo de Brouwer para funções definidas em triângulos de $\mathbb{R}^{2}$.

A motivação para este trabalho desde o início foi o consagrado Teorema de Monsky, que afirma que qualquer divisão de um quadrado em triângulos de mesma área que não se sobrepõem tem que ser feita com um número par de triângulos. Este resultado de enunciado simples e demonstração surpreendentemente não-trivial foi estudado inicialmente por Fred Richman. Em 1965, Richman era estudante de mestrado na Universidade do Novo México e deparou-se com essa questão durante sua preparação para o exame de qualificação. Ao fazer tentativas de dissecção para o quadrado, conjecturou que o enunciado era verdadeiro, mas não conseguiu ir além da verificação de casos particulares. Ele havia colocado o enunciado em sua ementa de qualificação, mas no insucesso de obter uma prova, acabou por retirar o problema da ementa. Nesta época, 
comunicou a conjectura a John Thomas, seu colega. O problema mostrou-se difícil e foi enviado para a American Mathematical Montly, que o publicou como "Problem 5479". Em 1968 o próprio Thomas publicou na Mathematics Magazine uma prova do resultado para o quadrado $[0,1] \times[0,1]$ e para divisões usando triângulos com vértices de coordenadas racionais de denominador ímpar (3), usando essencialmente ferramentas de geometria analítica.

Em 1970, Paul Monsky fornece em (4) uma prova para o caso geral usando valorações diádicas em uma belíssima demonstração que congrega ideias de combinatória e números diádicos. Nesta dissertação, apresentaremos o argumento de Monsky para a prova do seguinte enunciado à lá Thomas (Teorema 2.14): qualquer divisão de um quadrado em triângulos de mesma área e com vértices em $\mathbb{Q}^{2}$ tem um número par de triângulos. As técnicas que empregaremos são exatamente as mesmas para provar o caso de triângulos com vértices em $\mathbb{R}^{2}$ desenvolvidas por Monsky, mas dependem de extensões de valorações diádicas de $\mathbb{Q}$ para $\mathbb{R}$, algo bastante não-trivial e fora do escopo deste trabalho. Até onde sabemos, depois de quase 50 anos a prova de Monsky é a mais simples já produzida para o problema da divisão do quadrado em triângulos de mesma área. Tudo isso será tratado no Capítulo 2 desta dissertação. O resultado de Monsky foi estendido em 1979 por D.Mead em (5) para hipercubos $[0,1]^{n} \subset \mathbb{R}^{n}$ : seja $n \geqslant 3$. Suponha que $[0,1]^{n}$ está dividido em $m$ hiper-tetraedros de mesmo volume. Então $m$ é múltiplo de $n$ !.

No Capítulo 3, exporemos um lema de Sperner para triangulações de polígonos convexos e como aplicação, provaremos o teorema do ponto fixo de Brouwer. Em termos intuitivos, o lema de Sperner para triangulações diz que dada uma triangulação para um polígono e uma coloração dos vértices desta triangulação usando três cores, o número de triângulos "tricolores" que aparecem tem paridade controlada pelo número de segmentos "bicolores" na fronteira do polígono (Lema 3.2). Este lema pode ser estendido para "hiperpoliedros" de $\mathbb{R}^{n}$ e suas consequências ainda hoje são objeto de investigação. Como aplicação de nossos enunciados, provaremos a seguinte versão para o teorema do ponto fixo de Brouwer (Teorema 3.6): se $\mathbb{T} \subset \mathbb{R}^{2}$ é um triângulo e $f: \mathbb{T} \longrightarrow \mathbb{T}$ é contínua, então existe $p \in \mathbb{T}$ tal que $f(p)=p$.

No Capítulo 4, faremos a descrição do estudo realizado com alunos da educação básica, tendo como objetivo trabalhar conteúdos como paridade de números inteiros e combinatória e, principalmente, incentivar estudantes a conjecturar fatos e propor justificativas para a construção do conhecimento. As atividades foram motivadas por jogos de tabuleiros baseados nos lemas de Sperner. 


\section{2 \\ Lema de Sperner para segmentos}

Neste capítulo trataremos de uma versão do Lema de Sperner para segmentos e aplicações. Em particular, passaremos brevemente por alguns aspectos da teoria das valorações, dando especial atenção às valorações diádicas em $\mathbb{Q}$.

\section{1}

\section{Lema de Sperner}

Definição 2.1 Um segmento que tem um extremo colorido com uma cor $x$ e o outro extremo colorido com uma cor y é denominado aresta "xy" (Figura 2.1).

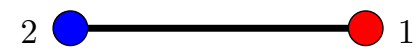

Figura 2.1: Um segmento "12".

Lema 2.2 (Lema de Sperner para segmentos) Se um segmento tem um extremo colorido com uma cor 1 e o outro extremo colorido com uma cor 2 e, sobre ele há finitos pontos marcados e coloridos com essas cores, então o número de arestas "12" sobre esse segmento é impar.

Demonstração. Considere um segmento $A D$, sendo o ponto $A$ colorido com a cor 1 e o ponto $D$ colorido com a cor 2 .

1. Se não colorirmos pontos entre $A$ e $D$, o segmento $A D$ será a única aresta "12". Então o número de arestas "12" sobre $A D$ é 1 . Logo, é ímpar.

2. A prova seguirá por indução. Suponha que se colorirmos $k$ pontos sobre o segmento $A D$ com as cores 1 e 2 , o número de arestas " 12 " sobre $A D$ seja ímpar. Para prosseguir a prova por indução, marcaremos mais um ponto do segmento $A D$ com a cor 1 ou 2. Este ponto estará em um segmento de tipo " $11 "$, " 22 " ou " 12 ".

Dessa forma, temos três casos a considerar:

(a) Colorindo um ponto da aresta "11" com a cor 1 não surgem arestas " 12 ". Colorindo um ponto com a cor 2 , temos duas novas arestas 
"12". Nas duas situações não alteramos a paridade do número de aresta "12", que continua ímpar.

(b) Na aresta " 22 " temos duas novas arestas "12" se colorimos um de seus pontos com a cor 1 e não temos novas arestas desse tipo se a cor 2 for usada. Nenhum desses casos alteram a paridade do número de aresta "12", que continua ímpar.

(c) Ao colorir um ponto com a cor 1 ou com a cor 2 sobre uma aresta "12" não alteramos a quantidade desse tipo de aresta, mantendo-a ímpar.

Em todos os possíveis casos temos que o número de arestas " 12 " sobre $A D$ é ímpar.

Corolário 2.3 Se os extremos do segmento AD têm ambos cor 1 ou ambos cor 2, o número de segmentos "12" sobre AD é par.

A seguir, apresentamos uma das interessantes aplicações desse lema de Sperner.

\section{2}

\section{Jogo dos Impactos}

O Jogo dos Impactos (6) é jogado por dois jogadores, $\mathcal{A}$ e $\mathcal{B}$, em um tabuleiro com $n$ casas. O jogador $\mathcal{A}$ recebe peças de cor $a$ e o jogador $\mathcal{B}$ recebe peças de cor $b$. O tabuleiro é como na Figura 2.2.

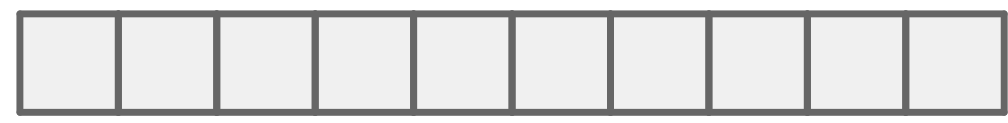

Figura 2.2: Um tabuleiro com $n=10$ casas.

As casas do tabuleiro serão preenchidas pelos jogadores $\mathcal{A}$ e $\mathcal{B}$ com as peças $a$ e $b$ seguindo as regras abaixo:

Regra 2.4 Os jogadores decidem quem começa a preencher o tabuleiro. Alternadamente, cada jogador coloca uma de suas peças em uma das casas não ocupadas do tabuleiro. Se duas casas vizinhas recebem cores distintas, temos um Impacto. O jogo termina quando todas as casas forem ocupadas. Para saber o vencedor, contam-se os impactos, ou seja, o número de adjacências de cores diferentes. Se essa quantidade for ímpar, o primeiro jogador vence. Se for par, quem vence o jogo é o segundo jogador. 
Para efeito de ilustração, as Figuras 2.3 e 2.4 representam um jogo no qual a cor $a$ será vermelha e a cor $b$ será azul.

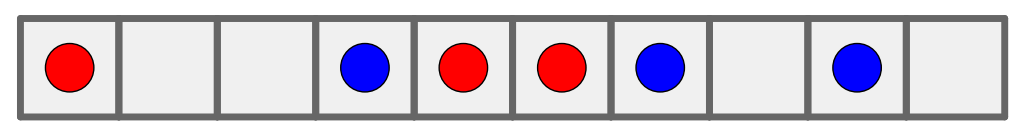

Figura 2.3: Jogo ainda não terminado. Jogador $\mathcal{A}$ (vermelho) começou.

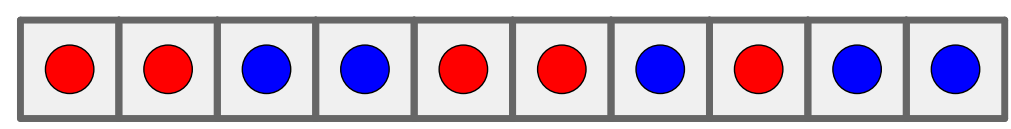

Figura 2.4: Jogo concluído, com vitória do Jogador $\mathcal{A}$.

A pergunta natural em qualquer jogo é se existe uma estratégia que garanta a vitória de um dos jogadores. Passamos a explorar essa questão para o Jogo dos Impactos.

Segundo o Lema 2.2 e seu corolário, a quantidade de impactos é ímpar se os extremos recebem cores distintas e par se recebem a mesma cor. Portanto, a vitória do jogo tem base nas casas das extremidades, independentemente do que acontece nas demais casas do tabuleiro. Observe que se o segundo jogador ocupar algum extremo do tabuleiro, o primeiro pode garantir a vitória em sua próxima jogada, ocupando o outro extremo. Isso nos faz pensar que uma boa estratégia de vitória para o primeiro jogador é aguardar seu oponente ocupar um extremo para em seguida ocupar o outro. De fato, essa é uma excelente estratégia. No entanto, se a última jogada for do segundo jogador, isso pode não acontecer. Ele pode não ocupar extremos até sua última jogada, que é a última jogada da partida. Nesse caso, o primeiro jogador deve ocupar um extremo em sua última jogada, que é a penúltima jogada da partida, e deixar o outro extremo para seu adversário, garantindo assim extremos de cores distintas e, portanto, sua vitória.

Buscando expor outras aplicações do Lema de Sperner, faremos um breve estudo das valorações diádicas em $\mathbb{Q}$, demonstrando algumas propriedades. 


\section{3}

\section{Valorações Diádicas}

Seja $x \in \mathbb{Q}$. Não é difícil verificar que existem únicos $a, b \in \mathbb{Z}$ co-primos (a menos de sinais) e $n \in \mathbb{N}$, tais que $x=2^{n} \frac{a}{b}$.

Definição 2.5 Sejam $x \in \mathbb{Q}-\{0\}, a, b \in \mathbb{Z}$ impares e $n \in \mathbb{Z}$ tais que $x=2^{n} \frac{a}{b}$. A valoração diádica de $x$ é definida por $|x|_{2}=\left(\frac{1}{2}\right)^{n}$. Se $x=0$, definimos $|x|_{2}=0$.

Exemplo 2.6 1. Se $x=\frac{12}{5}=\frac{2^{2} \cdot 3}{5}$, ent $\tilde{a} O|x|_{2}=\left|\frac{12}{5}\right|_{2}=\left(\frac{1}{2}\right)^{2}=\frac{1}{4}$

2. Se $x=\frac{18}{12}=\frac{2 \cdot 3^{2}}{2^{2} \cdot 3}=2^{-1} \cdot 3$, então $|x|_{2}=\left|\frac{18}{12}\right|_{2}=\left(\frac{1}{2}\right)^{-1}=2$

3. Se $x=27=2^{0} \cdot 3^{3}$, então $|x|_{2}=|27|_{2}=\left(\frac{1}{2}\right)^{0}=1$

4. Se $x=36=2^{2} \cdot 3^{2}$, então $|x|_{2}=|36|_{2}=\left(\frac{1}{2}\right)^{2}=\frac{1}{4}$

Valorações diádicas detectam números pares e números ímpares, no sentido do enunciado a seguir.

Lema 2.7 Seja $x \in \mathbb{Z}$. Então:

1. $|x|_{2}=1$ se e somente se $x$ é impar.

2. $0 \leqslant|x|_{2}<1$ se e somente se $x$ é par.

Demonstração. Para o item 1, observe que, se $x$ é um número ímpar, então não tem fator 2 em sua decomposição em primos, sendo do tipo $x=2^{0} a$, com $a$ ímpar. Logo, $|x|_{2}=\left(\frac{1}{2}\right)^{0}=1$. A recíproca é evidente.

Para o item 2, se $x$ é par, então tem o fator 2 em sua decomposição em primos, sendo do tipo $x=2^{n} \cdot a$, com $a$ ímpar e $n>0$. Logo, $|x|_{2}=\left(\frac{1}{2}\right)^{n}<1$. $\mathrm{e}$, por definição $|x|_{2} \geqslant 0$, valendo a igualdade somente se $x=0$. A recíproca é também bastante simples.

Seguimos com mais algumas propriedades das valorações diádicas em $\mathbb{Q}$.

Lema 2.8 A valoração diádica $|\cdot|_{2}: \mathbb{Q} \longrightarrow \mathbb{R}$ tem as seguintes propriedades:

1. $|x y|_{2}=|x|_{2}|y|_{2}$

2. $|x+y|_{2} \leqslant|x|_{2}+|y|_{2}$

3. Se $|x|_{2}<|y|_{2}$, então $|x+y|_{2}=|y|_{2}$

4. Se $|x|_{2}=|y|_{2}$, então $|x+y|_{2}<|x|_{2}$ e $|x+y|_{2}<|y|_{2}$ 
A demonstração desse lema encontra-se no Apêndice A.

Corolário 2.9 Para todo $x, y \in \mathbb{Q}$ vale $|x+y|_{2} \leqslant \max \left\{|x|_{2},|y|_{2}\right\}$.

Façamos aqui uma observação antes de prosseguirmos. A teoria de valorações é de fato bem mais geral do que apresentamos. Por exemplo, é possível definir valorações diádicas para números reais. O processo que parece natural (considerar limites de valorações de números racionais) não é adequado, porque embora a desigualdade triangular continue valendo para valorações diádicas, a noção de limite é diferente daquela induzida pelo módulo usual de números reais. O tratamento formal das valorações de números reais está fora do escopo desta dissertação, mas não podemos deixar de citar que tudo que é feito nesta dissertação para $\mathbb{Q}$ poderia ser feito para $\mathbb{R}$, mas dependeria de resultados mais profundos. Para uma referência no assunto, ver por exemplo (7), Capítulo XII.

\section{4}

\section{Uma coloração notável de $\mathbb{Q}^{2}$}

Sejam $Q_{1}, Q_{2}$ e $Q_{3}$ subconjuntos disjuntos que formam uma partição de $\mathbb{Q}^{2}$ definidos por:

$$
\begin{aligned}
Q_{1} & =\left\{(x, y):|x|_{2}<1,|y|_{2}<1\right\} \\
Q_{2} & =\left\{(x, y):|x|_{2} \geqslant 1,|x|_{2} \geqslant|y|_{2}\right\} \\
Q_{3} & =\left\{(x, y):|y|_{2} \geqslant 1,|x|_{2}<|y|_{2}\right\}
\end{aligned}
$$

A cada conjunto $Q_{i}$ acima associamos uma cor $i$. Assim, colorimos os pontos do plano $\mathbb{Q}^{2}$ usando três cores distintas. Essa coloração disjunta de $\mathbb{Q}^{2}$ apresenta propriedades surpreendentes que provaremos nos lemas a seguir. A Figura 2.5 mostra uma coloração de $[0,1] \times[0,1]$ com $84 \times 83$ pontos igualmente espaçados. Na Figura 2.6 há uma coloração de $\left[0, \frac{355}{339}\right] \times\left[0, \frac{355}{339}\right]$ com $51 \times 51$ pontos igualmente espaçados. Nessas figuras, $Q_{1}$ é a cor vermelha, $Q_{2}$ é a cor verde e $Q_{3}$ é a cor azul. 


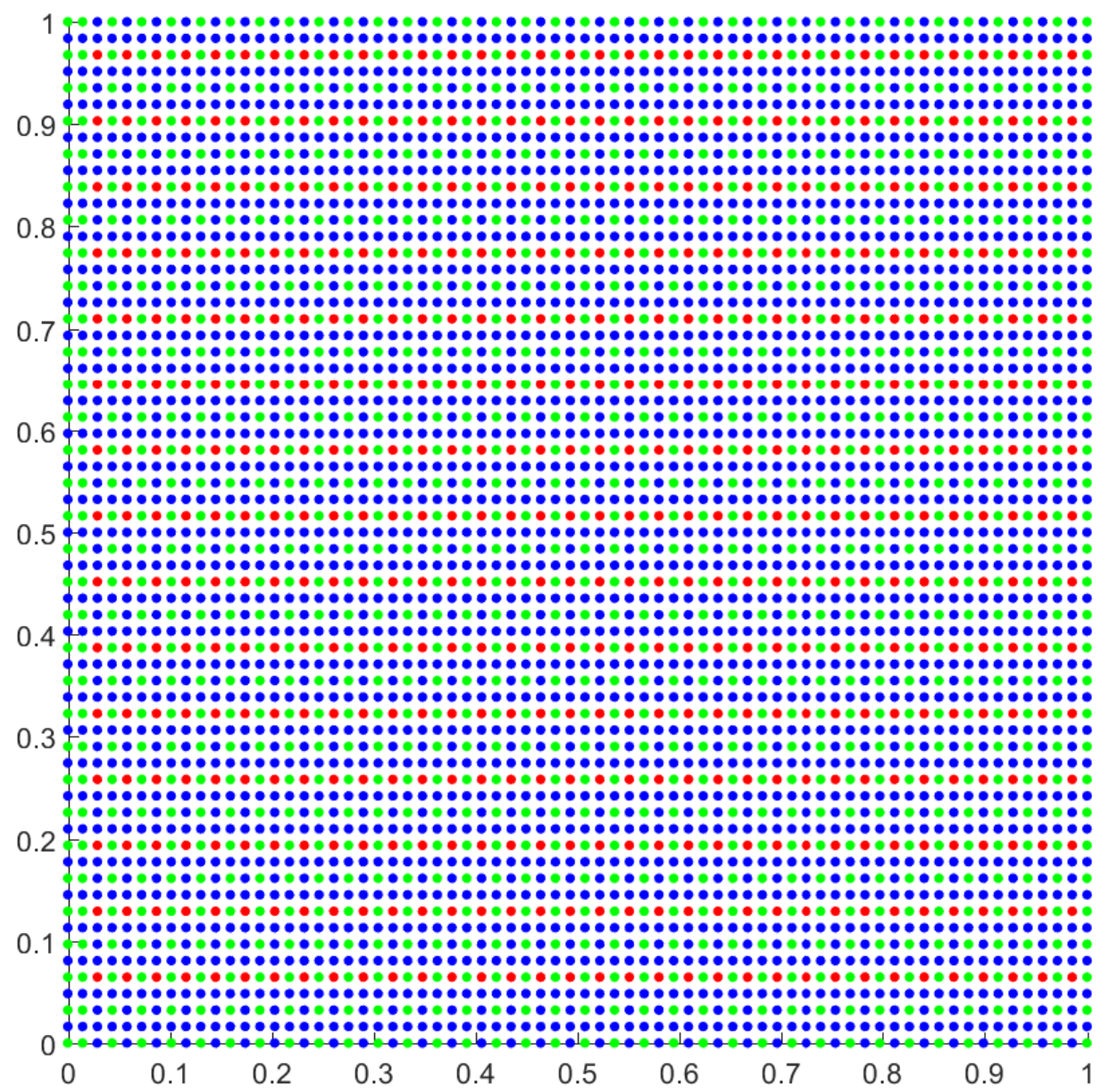

Figura 2.5: Coloração de $84 \times 83$ pontos em $[0,1] \times[0,1]$. 


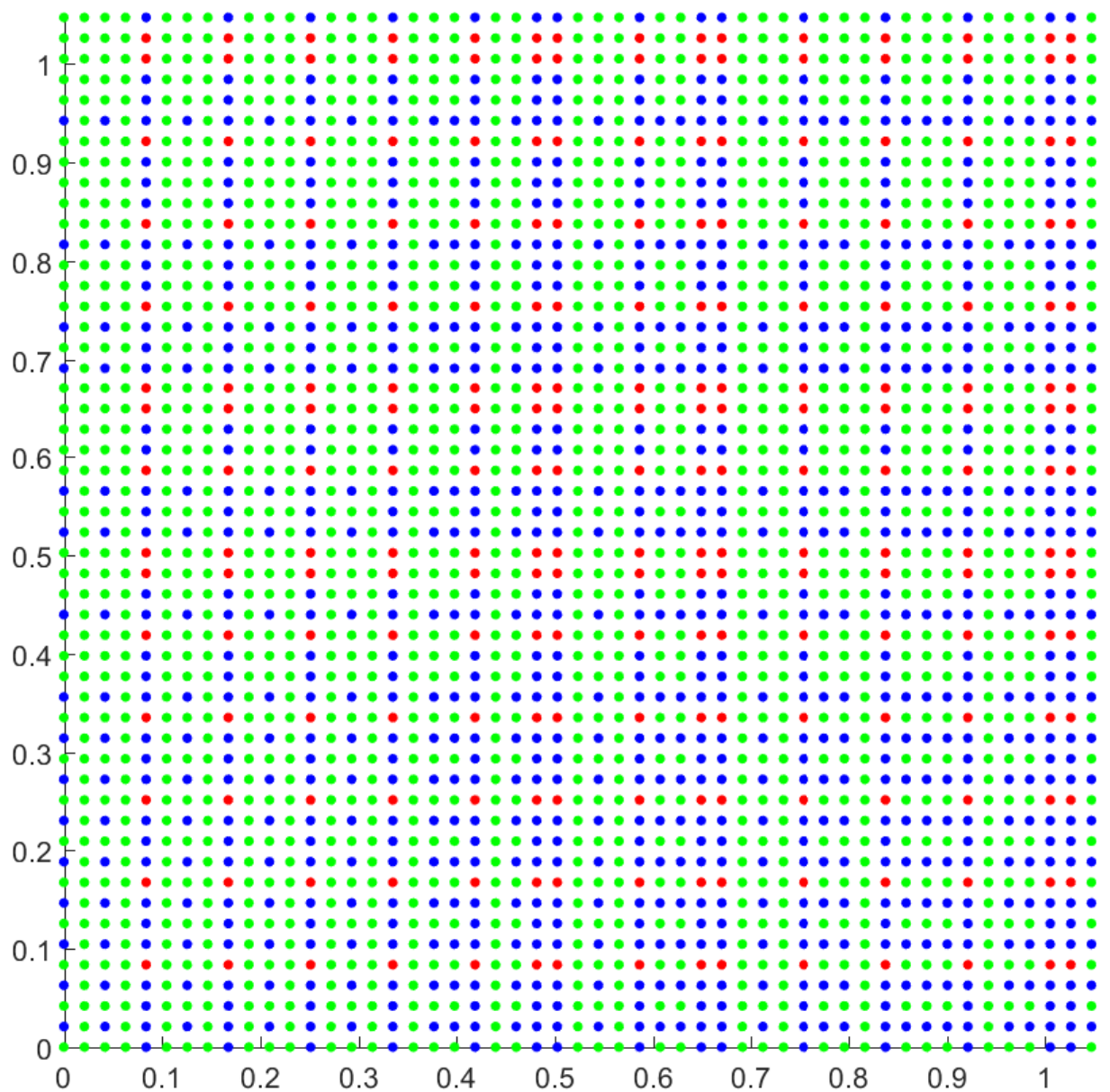

Figura 2.6: Coloração de $51 \times 51$ pontos em $\left[0, \frac{355}{339}\right] \times\left[0, \frac{355}{339}\right]$.

Lema 2.10 $Q_{2}$ e $Q_{3}$ são invariantes por translação de pontos de $Q_{1}$, isto é:

$$
\begin{aligned}
& \text { 1. }\left(x_{1}, y_{1}\right) \in Q_{1} \text { e }\left(x_{2}, y_{2}\right) \in Q_{2} \Longrightarrow\left(x_{1}+x_{2}, y_{1}+y_{2}\right) \in Q_{2} \\
& \text { 2. }\left(x_{1}, y_{1}\right) \in Q_{1} e\left(x_{3}, y_{3}\right) \in Q_{3} \Longrightarrow\left(x_{1}+x_{3}, y_{1}+y_{3}\right) \in Q_{3}
\end{aligned}
$$

A demonstração desse lema encontra-se no Apêndice B.

Definição 2.11 Um triângulo que tem um vértice de cor 1, um vértice de cor 2 e um vértice de cor 3 , é denominado triângulo completo (Figura 2.7).

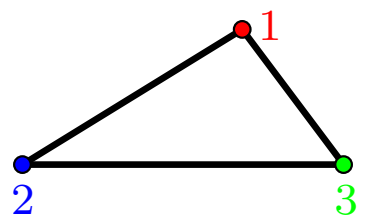

Figura 2.7: Um triângulo completo. 
Lema 2.12 (lema da área) Se um triângulo de vértices em $\mathbb{Q}^{2}$ é completo e tem área $S$, então $|S|_{2}>1$.

Demonstração. Sejam $A \in Q_{1}, B \in Q_{2}$ e $C \in Q_{3}$, vértices de um triângulo completo, de área $S$. Como $Q_{2}$ e $Q_{3}$ são invariantes por translação de pontos de $Q_{1}$ e, claramente, $(0,0) \in Q_{1}$, podemos supor que o triângulo tem um vértice na origem (Figura 2.8).
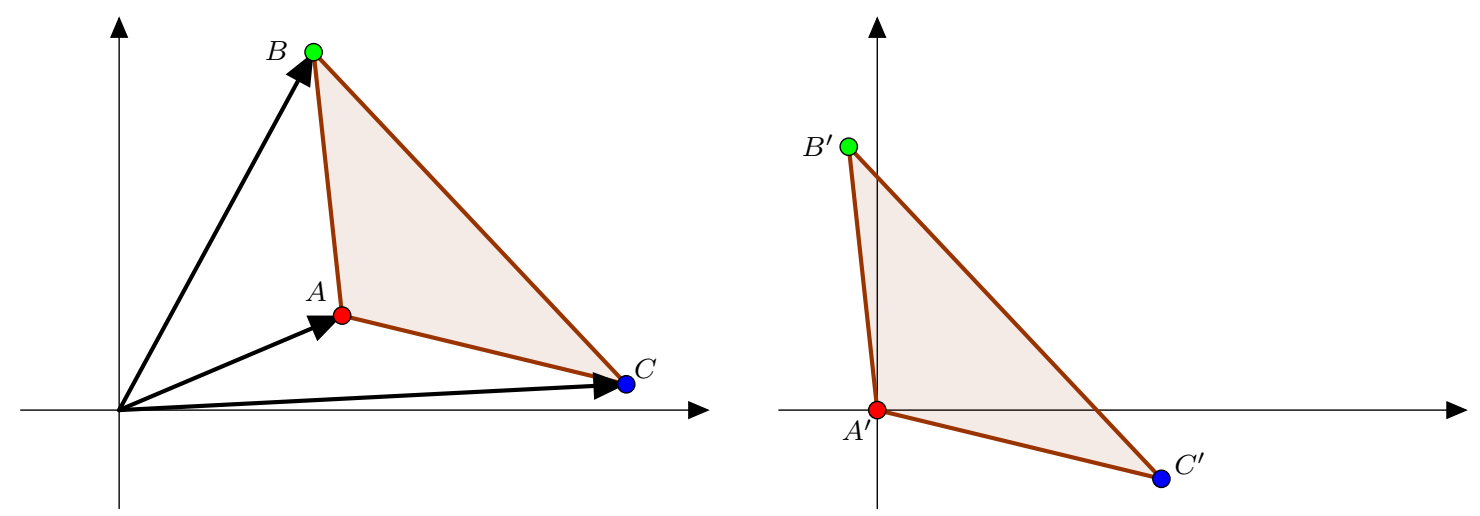

Figura 2.8: Translação de um triângulo.

De fato, observe que $\overrightarrow{A^{\prime} B^{\prime}}=\overrightarrow{A^{\prime} B}-\overrightarrow{A^{\prime} A}=B-A$ e $\overrightarrow{A^{\prime} C^{\prime}}=\overrightarrow{A^{\prime} C}-\overrightarrow{A^{\prime} A}=C-A$, então $B^{\prime}=B-A$ e $C^{\prime}=C-A$. Além disso, se $A \in Q_{1}$ então $-A \in Q_{1}$. Assim,

$$
\begin{aligned}
& (B+A) \in Q_{2} \Longrightarrow(B-A) \in Q_{2} \\
& (C+A) \in Q_{3} \Longrightarrow(C-A) \in Q_{3}
\end{aligned}
$$

Portanto, $B^{\prime} \in Q_{2}$ e $C^{\prime} \in Q_{3}$. Sendo $B=\left(x_{2}, y_{2}\right) \in Q_{2}$ e $C=\left(x_{3}, y_{3}\right) \in Q_{3}$, temos $\left|x_{2}\right|_{2} \geqslant\left|y_{2}\right|_{2}$ e $\left|y_{3}\right|_{2}>\left|x_{3}\right|_{2}$. Então $\left|x_{2}\right|_{2}\left|y_{3}\right|_{2}>\left.\left.\left|y_{2}\right|_{2}\right|_{3}\right|_{2}$. Assim, $\left|x_{2} y_{3}\right|_{2}>\left|y_{2} x_{3}\right|_{2}$ e, pela propriedade 3 do Lema $2.8,\left|x_{2} y_{3}-y_{2} x_{3}\right|_{2}=\left|x_{2} y_{3}\right|_{2}$.

Agora, observe que o triângulo $\mathrm{ABC}$ de vértices $A=(0,0), B=\left(x_{2}, y_{2}\right)$ e $C=\left(x_{3}, y_{3}\right)$, tem área $S=\left|\frac{x_{2} y_{3}-x_{3} y_{2}}{2}\right|$. Dessa forma,

$$
\begin{aligned}
|S|_{2} & =\left|\frac{x_{2} y_{3}-y_{2} x_{3}}{2}\right|_{2} \\
& =\left|\frac{1}{2}\right|_{2}\left|x_{2} y_{3}-y_{2} x_{3}\right|_{2} \\
& =2\left|x_{2} y_{3}\right|_{2} \\
& =2\left|x_{2}\right|_{2}\left|y_{3}\right|_{2} .
\end{aligned}
$$

Pelas definições de $Q_{2}$ e $Q_{3},\left|x_{2}\right|_{2} \geqslant 1$ e $\left|y_{3}\right|_{2} \geqslant 1$. Então, $\left.\left.\left|x_{2}\right|_{2}\right|_{3}\right|_{2} \geqslant 1$ e $|S|_{2}=2\left|x_{2}\right|_{2}\left|y_{3}\right|_{2} \geqslant 2$. Portanto, $|S|_{2}>1$. 
Observando o aspecto geométrico nada previsível da distribuição de cores nas Figuras 2.5 e 2.6, o próximo lema é certamente um resultado notável.

Lema 2.13 Qualquer reta do plano tem no máximo pontos de duas cores distintas.

Demonstração. Se uma reta contivesse três pontos de cores distintas, a reta conteria um triângulo completo de área $S$, tal que $|S|_{2}>1$, pelo lema da área (Lema 2.12). Mas isso é impossível, pois os vértices são colineares, fazendo com que o triângulo tenha área nula.

Com base nos resultados anteriores, discutimos na próxima seção um interessante resultado geométrico conhecido como teorema de Monsky.

\section{5}

\section{O teorema de Monsky}

Passamos a explorar, usando as ferramentas acima, a prova de uma versão "fraca" do Teorema de Monsky (4), baseados em suas ideias originais.

Teorema 2.14 (Monsky) Toda dissecção do quadrado $P=[0,1] \times[0,1] \mathrm{em}$ triângulos de mesma área e vértices em $\mathbb{Q}^{2}$ tem um número par de triângulos.

Demonstração. Sejam $A=(0,0), B=(0,1), C=(1,1)$ e $D=(1,0)$. Considere uma dissecção de $P$ em $m$ triângulos de mesma área e vértices em $\mathbb{Q}^{2}$. Considere também a coloração $Q_{1}, Q_{2}$ e $Q_{3}$ de $\mathbb{Q}^{2}$, definida anteriormente, para colorir os vértices dessa triangulação.

Note que $A \in Q_{1}, B \in Q_{3}, C \in Q_{2}$ e $D \in Q_{2}$. Assim, pelo Lema 2.13, sobre o lado $A B$ só há pontos de cores 1 e 3 , sobre $B C$ só há pontos de cores 2 e 3 e sobre $A D$ só há pontos de cores 1 e 2 . Além disso, sobre o lado $C D$ não há pontos de cor 1 , pois se $(x, y) \in Q_{1}$ temos $|x|_{2}<1$ e se $(x, y) \in C D$ temos $|x|_{2}=|1|_{2}=1$, já que os pontos de $C D$ são do tipo $(1, y)$. Dessa forma, as arestas " 12 " do bordo do quadrado ocorrem apenas sobre o lado $A D$. Portanto, pelo Lema de Sperner para segmentos (Lema 2.2), o número de arestas "12" no bordo do quadrado é ímpar.

Afirmamos que os únicos triângulos da dissecção que têm um número ímpar de arestas "12" em seus lados são os triângulos completos. Para isso é relevante lembrar que, pelo Lema 2.13, em cada linha da dissecção aparecem pontos de no máximo duas cores distintas e que, pelo Lema 2.2, um segmento com extremos de cores 1 e 2 contém um número ímpar de segmentos " 12 ". Faremos a prova desta afirmação em três casos: 
1. Triângulos que têm todos os vértices da mesma cor.
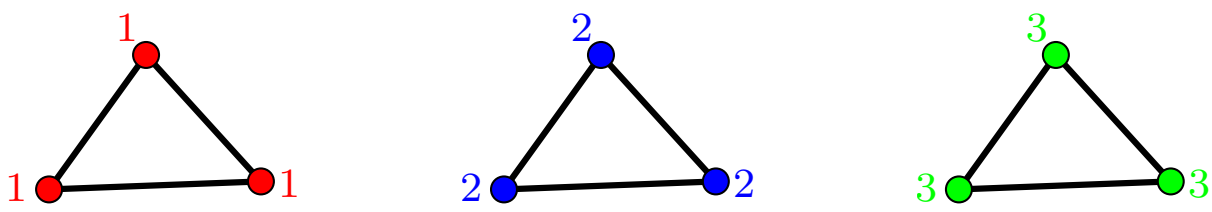

Figura 2.9: Vértices da mesma cor.

Se todos os vértices têm cor 3, pelo Lema 2.13, não é possível haver cor 1 e cor 2, simultaneamente, sobre um mesmo lado do triângulo. Portanto, não há arestas " 12 " nos lados do triângulo e, assim, o número de arestas "12" é par.

Se todos os vértices têm a cor 1 ou todos têm a cor 2, pelo Corolário 2.3 , o número de arestas " 12 " em cada lado do triângulo é par e o total também.

2. Triângulos que têm vértices de duas cores.
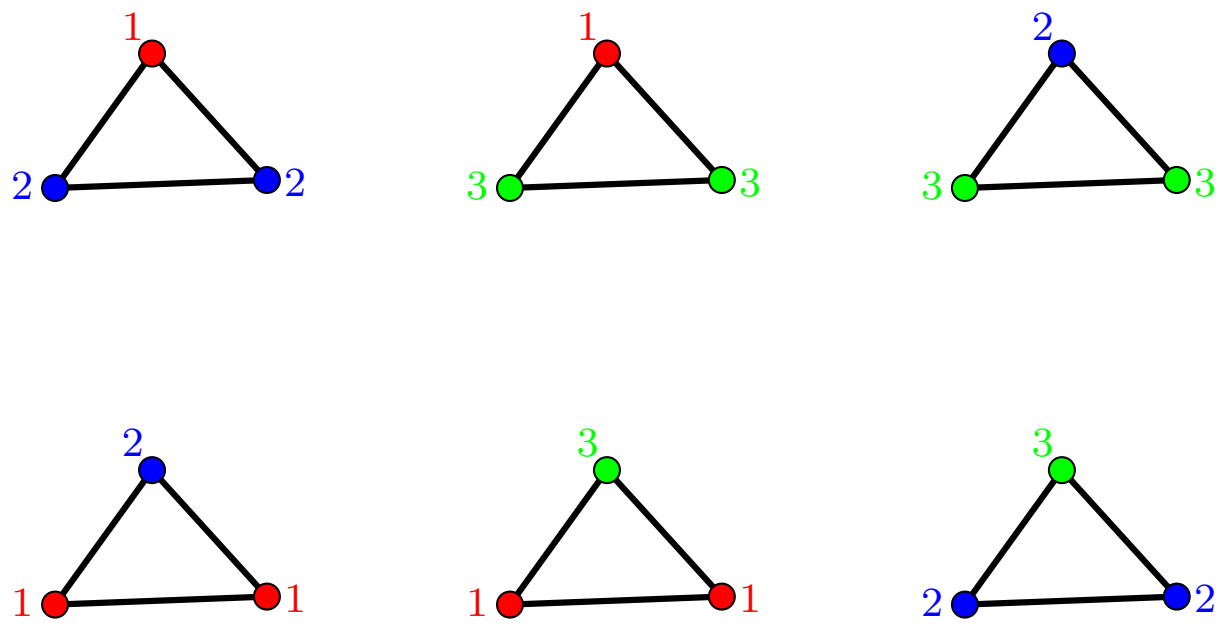

Figura 2.10: Vértices de duas cores.

Usando as cores 3 e 2 nos vértices, pelo Lema 2.13 não haverá a cor 1 sobre os lados do triângulo. Da mesma forma, usando as cores 3 e 1, não haverá a cor 2. Portanto, nessas duas situações o número de segmentos "12" nos lados do triângulo é par.

Se os vértices têm cores 1 e 2 , teremos uma quantidade par de arestas "12" sobre o lado do triângulo cujos extremos foram marcados com a mesma 
cor, e uma quantidade ímpar sobre os outros dois lados, que tiveram seus extremos marcados de cores distintas, totalizando um número par de arestas " 12 " sobre os lados desse triângulo.

3. Triângulo completo.

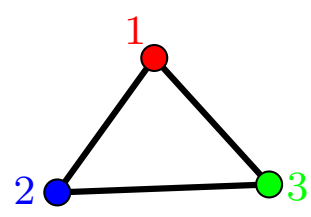

Figura 2.11: Triângulo completo.

Se o triângulo é completo, seus lados são do tipo "12", "23" e "13". Como sobre o lado do tipo "23" só ocorrem as cores 2 e 3 e sobre o lado "13" só as cores 1 e 3 , as arestas do tipo "12" só ocorrem sobre o lado " 12 ". Pelo Lema 2.2 , a quantidade de arestas " 12 " sobre um segmento de extremos coloridos com as cores 1 e 2 é ímpar. Portanto, um triângulo completo tem um número ímpar de arestas "12" em seus lados.

Assim, encerramos a prova de que os únicos triângulos da dissecção que têm um número ímpar de arestas " 12 " em seus lados são os triângulos completos.

Afirmamos agora que em qualquer dissecção do quadrado em triângulos de vértices em $\mathbb{Q}^{2}$ há triângulo completo. De fato, somando o número de arestas "12" de todos os triângulos da dissecção, isso resulta em um número ímpar, pois cada aresta do interior do quadrado é contada duas vezes e as arestas do bordo, que têm quantidade ímpar, uma única vez. Se não existissem triângulos completos, essa soma seria par, já que cada triângulo não completo tem um número par de arestas " 12 ".

Com as duas afirmações anteriores, podemos encerrar a prova do teorema de Monsky: como a dissecção do quadrado $P=[0,1] \times[0,1]$ foi feita em $m$ triângulos de mesma área, digamos $S$, temos $m S=1$. Assim,

$$
|m S|_{2}=|m|_{2}|S|_{2}=|1|_{2}
$$

Além disso, como pelo menos um triângulo da dissecção é completo, pelo lema da área (Lema 2.12) temos que $|S|_{2}>1$. Então, $|m|_{2}<1$. Portanto, pelo Lema 2.7, $m$ é par. 
Como mencionado no início da seção, as ideias acima dão conta de um caso particular (vértices dos triângulos da dissecção em $\mathbb{Q}^{2}$ ) do teorema de Monsky. O caso geral pode ser assim enunciado:

Teorema 2.15 (Monsky, (4)) Toda dissecção do quadrado $P=[0,1] \times[0,1]$ em triângulos de mesma área tem um número par de triângulos.

A prova desta versão segue exatamente o mesmo argumento apresentado. Entretanto, há a clara dificuldade de estender os resultados sobre valorações diádicas em $\mathbb{Q}$ para $\mathbb{R}$. Sobre essa dificuldade já havíamos dedicado algumas linhas no final da Seção 2.3. Sugerimos (8) para um tratamento um pouco mais completo sobre tais dificuldades. 


\section{3 \\ Lema de Sperner para triangulações}

Os resultados apresentados a seguir apareceram pela primeira vez em (1) e desde então têm se consagrado como ferramentas úteis em combinatória e computação. Ao final deste capítulo apresentamos algumas aplicações.

\section{1}

\section{Lema de Sperner}

Definição 3.1 Uma triangulação $\tau$ de um polígono $P$ é um conjunto de triângulos $\tau=\left\{T_{i}\right\}_{i=1}^{n}$ tal que $P=T_{1} \cup \cdots \cup T_{n}$ satisfazendo: dois triângulos quaisquer de $\tau$ têm somente um vértice em comum, um lado comum ou não têm pontos comuns e os vértices de $P$ são vértices de $\tau$.
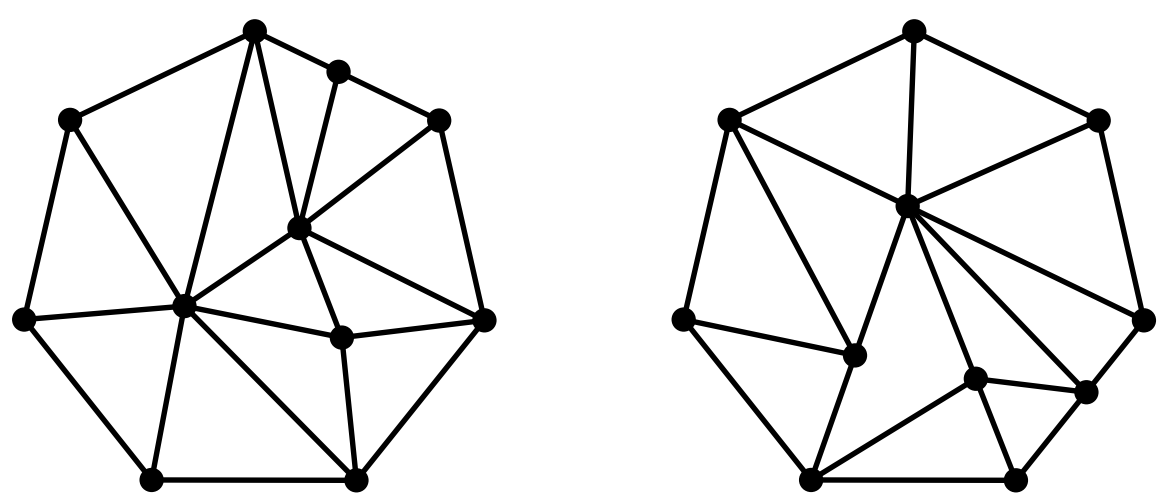

Figura 3.1: Uma triangulação e uma não-triangulação do heptágono regular.

Lembramos que um triângulo completo é aquele cujos vértices são coloridos por três cores distintas. A seguir enunciamos o principal resultado deste capítulo.

Lema 3.2 (Lema de Sperner para triangulações) Seja $P$ um polígono e $\tau$ uma triangulação de P. Se colorirmos os vértices de $\tau$ com cores distintas 1, 2 e 3, então o número de triângulos completos de $\tau$ tem mesma paridade que o número de arestas "12" contidas nos lados de P. 


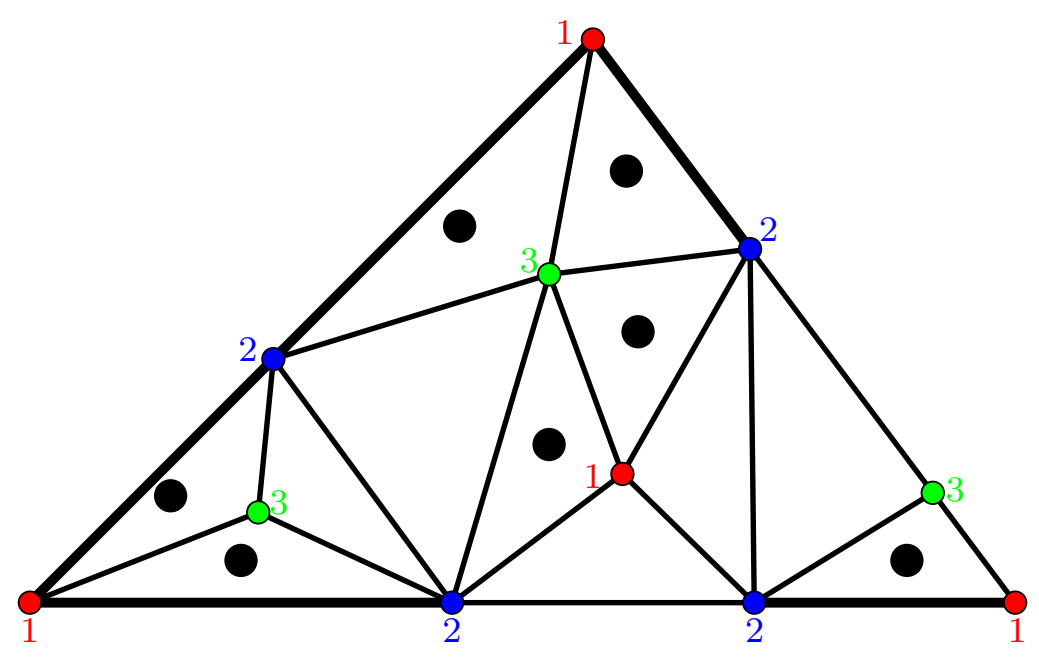

Figura 3.2: Uma triangulação de $P$ com 7 triângulos completos e 5 arestas " 12 " nos lados de $P$.

Demonstração. Suponha dada uma triangulação $\tau$ de $P$ e uma coloração de seus vértices usando cores 1,2 e 3 . Desenhe um ponto de cada lado de cada aresta "12" da triangulação, como na Figura 3.3. A paridade do total de pontos desenhados no interior do polígono será comparada com a paridade do número de arestas "12" de $P$ e com o número de triângulos completos de $\tau$.

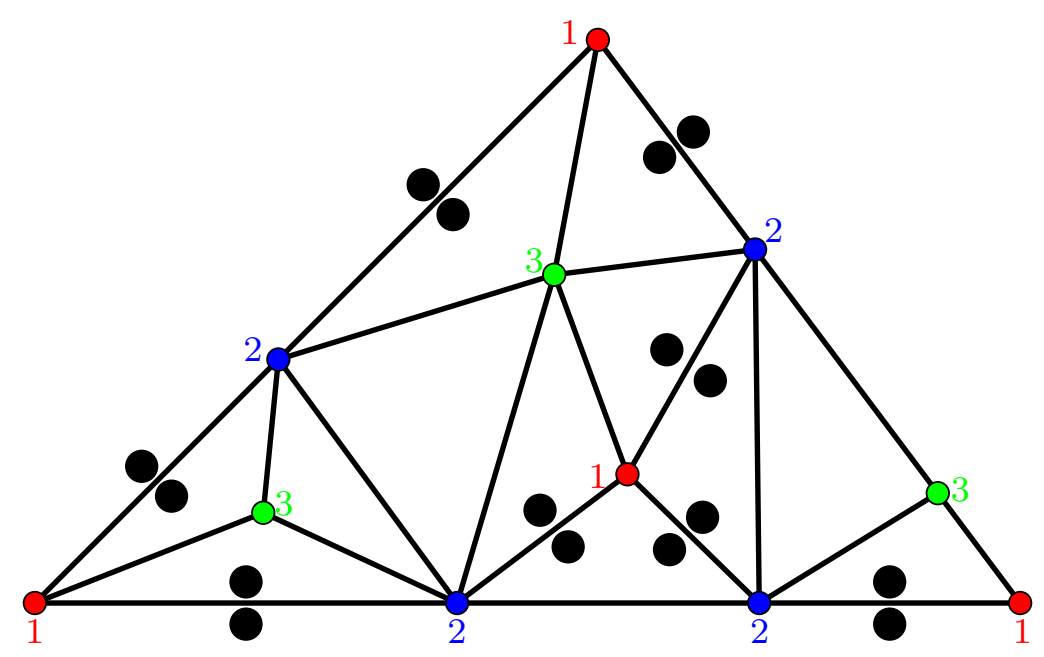

Figura 3.3: Uma triangulação de $P$ e pontos auxiliares para contagem.

Como os pontos são desenhados ao lado das arestas "12", o total de pontos desenhados depende apenas do total de arestas "12" da triangulação. E mais: para este total, arestas " 12 " contribuem com 2 pontos quando estão no interior de $P$ e com 1 ponto quando estão sobre os lados de $P$. 
Dessa forma, os pontos desenhados ao lado das arestas internas não interferem na paridade da quantidade total de pontos desenhados. Então, o total de pontos colocados no interior do polígono e o número de arestas " 12 " contidas nos lados de $P$ têm mesma paridade.

Agora vamos comparar o número de pontos colocados no interior de $P$ com o número de triângulos completos de sua triangulação. Provaremos que essas duas quantidades têm mesma paridade.

Cada triângulo da triangulação do polígono $P$ pode conter em seu interior 0, 1 ou 2 pontos por nós desenhados, dependendo do número de arestas " 12 " que o delimitam. Afirmamos que não é possível um triângulo de $\tau$ ter mais de duas arestas "12". De fato, se o triângulo é completo, tem uma única aresta "12" (e, portanto, contém apenas um ponto desenhado). Se o triângulo não é completo, pode ter duas arestas " 12 " (e, nesse caso, conter dois pontos desenhados) ou pode não ter aresta "12" (e não conter pontos desenhados), provando nossa afirmação.

Como consequência, a quantidade de pontos desenhados dentro de um triângulo não completo é par (0 ou 2). Com isso, a paridade do total do número de pontos desenhados no interior do polígono é igual à paridade do número de triângulos completos de $\tau$. Como havíamos concluído que essa paridade é igual à paridade de arestas "12" de $\tau$ que estão sobre os lados de $P$, temos que o número de triângulos completos de $\tau$ tem a mesma paridade que o número de arestas " 12 " contidos nos lados de $P$, como queríamos demonstrar.

Vale ressaltar que esse lema não garante a existência de triângulos completos na triangulação. Essa existência fica assegurada se, por exemplo, tivermos um número ímpar de arestas " 12 " nos lados do polígono. Enunciamos uma consequência dessa observação como um corolário, que será útil mais adiante.

Corolário 3.3 Seja T um triângulo cujos vértices têm cores distintas 1, 2 e 3. Considere uma triangulação $\tau$ de $T$ e uma coloração dos vértices de $\tau$ de tal modo que ao longo dos lados ij de $T$ não há vértices de $\tau$ de cor $k$ (com $i, j, k=1,2,3)$. Então há um triângulo completo em $\tau$.

Demonstração. Pelas hipóteses, sobre o lado "12" do triângulo há apenas pontos de cor 1 e 2. Pelo Lema 2.2 há um número ímpar de segmentos "12" no bordo de $T$. Pelo Lema 3.2 o número de triângulos completos de $\tau$ é ímpar e, portanto, positivo.

Não é difícil criar um exemplo de triangulação colorida na qual existem triângulos completos e não há arestas " 12 " no bordo do polígono. Nesse caso, 
teremos uma quantidade par triângulos completos, já que o polígono tem, sobre seus lados, uma quantidade par (zero) de arestas "12".

É possível, também, construir uma triangulação que tem arestas "12" no bordo, mas sem triângulos completos. Note que os vértices do triângulo original neste caso têm as três cores (Figura 3.4).

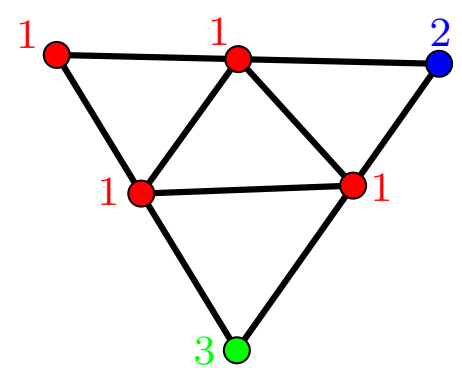

Figura 3.4: Triangulação sem triângulos completos.

A seguir apresentamos um jogo que aborda, com suas regras, tanto o lema de Sperner para segmentos (Lema 2.2) quanto o lema de Sperner para triangulações (Lema 3.2).

\section{2 \\ O Jogo de Sperner}

O Jogo de Sperner (9) ocorre em um tabuleiro triangular cujos vértices são marcados com três cores distintas, cor 1 (vermelha), cor 2 (azul) e cor 3 (verde). Nesse triângulo estará dada uma triangulação, como no exemplo da Figura 3.5.

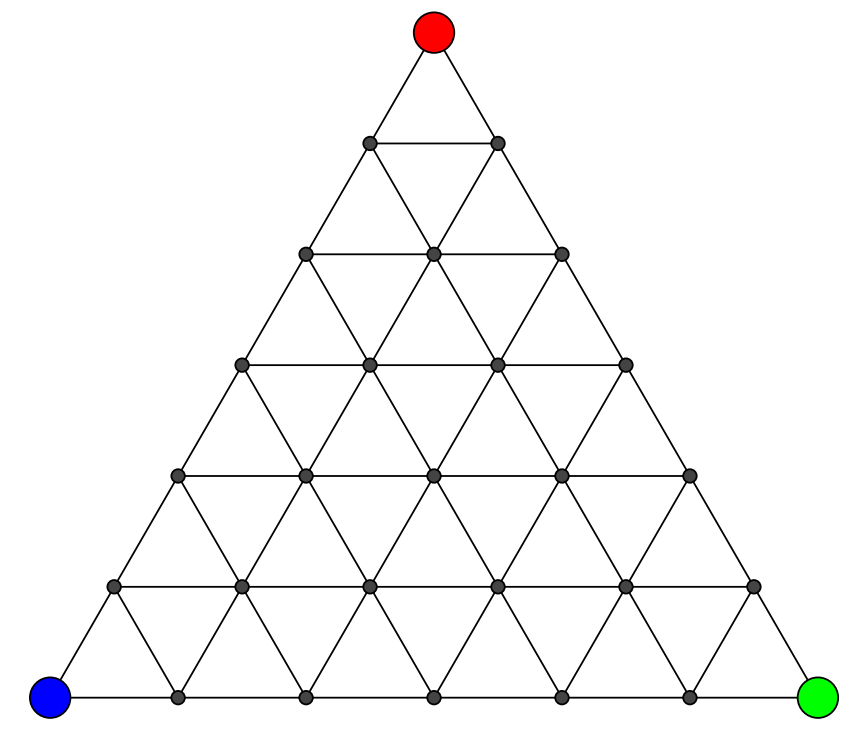

Figura 3.5: Um tabuleiro com 6 arestas em cada lado. 
O jogo é disputado por dois jogadores. Após sorteado quem inicia, os jogadores, alternadamente, colocam uma peça de qualquer uma das três cores (vermelha, azul ou verde) em um dos vértices ainda não preenchido da triangulação, seguindo uma única regra:

Regra 3.4 Sobre os lados do tabuleiro triangular só podem ser usadas peças das cores de seus extremos. O jogo termina quando um jogador fecha um triângulo completo, dando a vitória ao outro jogador (Figura 3.6).

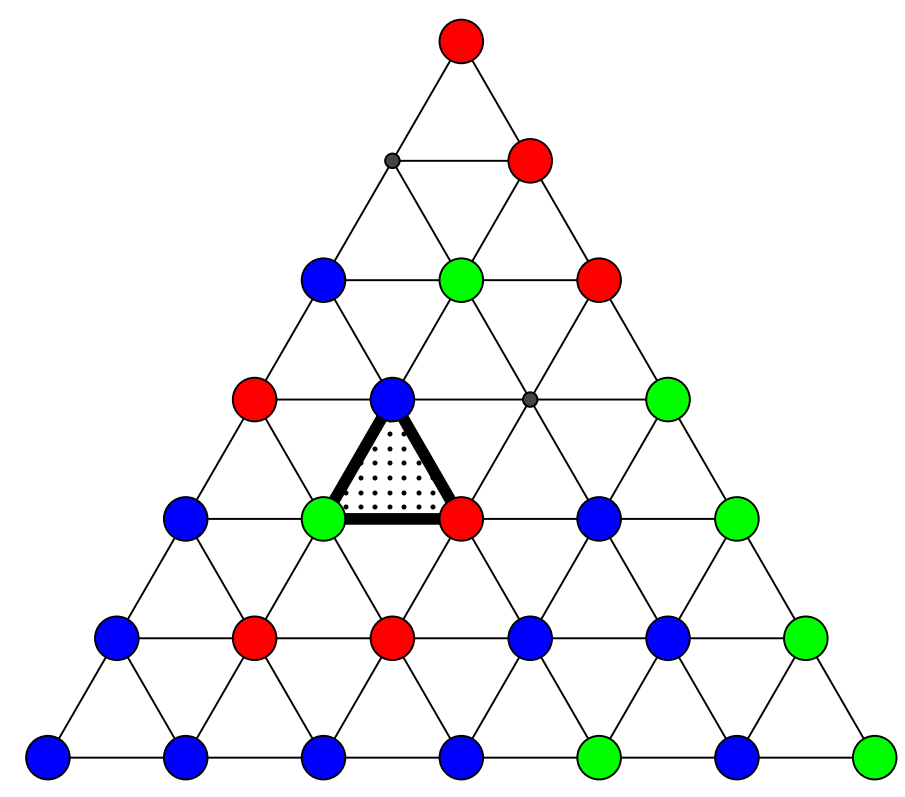

Figura 3.6: Um jogo encerrado.

Corolário 3.5 O jogo de Sperner nunca acaba em empate.

Demonstração. É simplesmente uma instância do Corolário 3.3. Só haveria empate no jogo se não existisse triângulo completo após todos os vértices serem prenchidos. Mas a definição do tabuleiro e a regra de colocação das peças garantem, pelos lemas de Sperner, a existência de pelo menos um triângulo completo. De fato, como os pontos dos lados do triângulo só podem ser marcados com as cores de seus extremos, o lema de Sperner para segmentos (Lema 2.2) assegura que a quantidade de arestas "12" no lado do triângulo é ímpar. Portanto, pelo lema de Sperner para triangulações (Lema 3.2) existirá um triângulo completo, impossibilitando o empate.

Na próxima seção apresentamos uma interessante aplicação em topologia do Lema de Sperner para triangulações. 


\section{3}

\section{Teorema do ponto fixo de Brouwer para um triângulo em $\mathbb{R}^{2}$}

Nesta seção consideraremos triângulos como polígonos de três lados incluindo seu interior. Se $\mathcal{A}$ é um conjunto não vazio, diremos que $a \in \mathcal{A}$ é ponto fixo de uma função $f: \mathcal{A} \longrightarrow \mathcal{A}$ se $f(a)=a$.

Teorema 3.6 (Ponto Fixo de Brouwer) $S e \mathbb{T} \subset \mathbb{R}^{2}$ é um triângulo e a função $f: \mathbb{T} \longrightarrow \mathbb{T}$ é contínua, então existe $p \in \mathbb{T}$ tal que $f(p)=p$.

Demonstração. Considere, sem perda de generalidade, o triângulo $\mathbb{T}$ de vértices $A=(1,0), B=(0,0)$ e $C=\left(\frac{1}{2}, \frac{1}{2}\right)$. Seja $\triangle$ o conjunto dos pontos das arestas e vértices de $\mathbb{T}$. Se houver algum ponto fixo de $f$ em $\triangle$, não há o que provar. Senão, $f(p) \neq p, \forall p \in \triangle$. Então $f(p)-p \neq 0$ para todo $p \in \triangle$.

Nesse caso, considere a função contínua $g: \mathbb{T} \longrightarrow \mathbb{R}^{2}$ definida por $g(p)=f(p)-p$ e a seguinte coloração de $\mathbb{T}$ :

- $p$ tem cor 1 se $g(p)=(x, y)$ satisfaz $x<0$ e $y \geqslant 0$

- $p$ tem cor 2 se $g(p)=(x, y)$ satisfaz $x \geqslant 0$ e $y \geqslant 0$

- $p$ tem cor 3 se $g(p)=(x, y)$ satisfaz $y<0$.
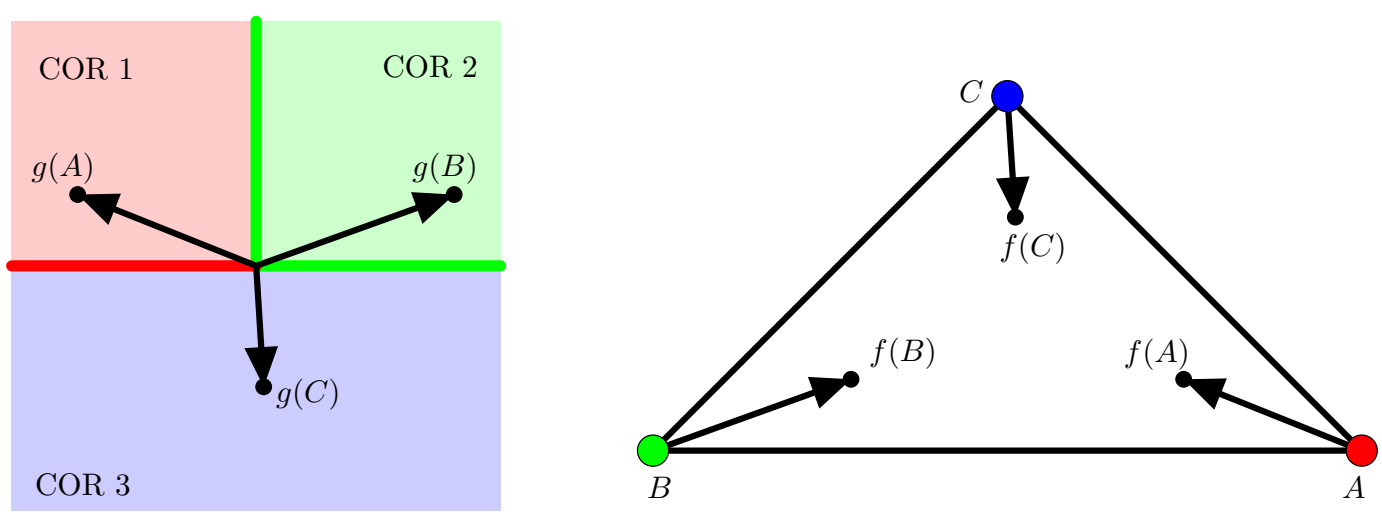

Figura 3.7: Esquema de coloração aplicado aos vértices de $\mathbb{T}$.

Com essa coloração e como a imagem de $f$ está contida em $\mathbb{T}$, no triângulo $A B C$ da Figura 3.7, o vértice $A$ tem cor 1 , o vértice $B$ tem cor 2 , o vértice $C$ tem cor 3, o lado $A B$ tem somente pontos de cores 1 e 2, o lado $B C$ tem apenas pontos de cores 2 e 3 e o lado $A C$ apenas pontos de cores 1 e 3 .

Nessas condições, dada uma triangulação, o Lema 2.2 garante que há um número ímpar de segmentos "12" no bordo do triângulo (e estão exatamente sobre o lado $A B$ ). Com isso, pelo Lema 3.2 , toda triangulação de $\mathbb{T}$ tem algum triângulo completo. 
Construiremos, agora, triangulações convenientes de $\mathbb{T}$. Para cada $n \in \mathbb{N}$, divida os lados de $\mathbb{T}$ em $n$ partes iguais e trace paralelas aos lados do triângulo passando pelos pontos dessas divisões, como na Figura 3.8.
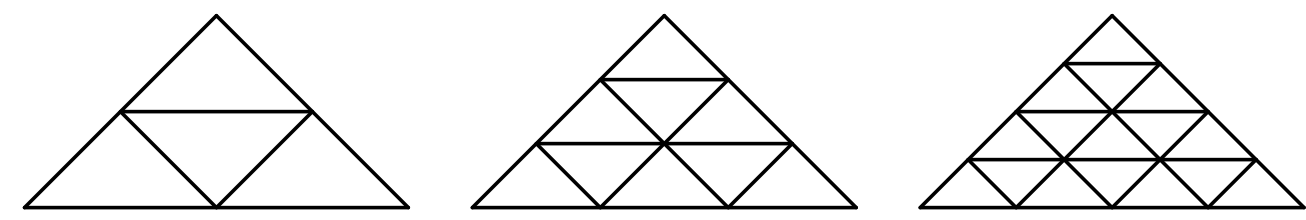

Figura 3.8: Triangulações de $\mathbb{T}$ para $n=2, n=3$ e $n=4$ respectivamente.

Para cada $n$, há um triângulo completo na $n$-ésima triangulação, digamos $\mathbb{T}_{n}$, e o diâmetro de $\mathbb{T}_{n}$ converge para zero quando $n \rightarrow \infty$. Denotamos por $v_{1}^{n}, v_{2}^{n}$ e $v_{3}^{n}$ os vértices de $\mathbb{T}_{n}$, que têm cores 1,2 e 3 , respectivamente. Por definição,

$-g\left(v_{1}^{n}\right)=\left(x_{1}^{n}, y_{1}^{n}\right)$, tem $x_{1}^{n}<0$ e $y_{1}^{n} \geqslant 0$

- $g\left(v_{2}^{n}\right)=\left(x_{2}^{n}, y_{2}^{n}\right)$ tem $x_{2}^{n} \geqslant 0$ e $y_{2}^{n} \geqslant 0$

$-g\left(v_{3}^{n}\right)=\left(x_{3}^{n}, y_{3}^{n}\right)$ tem $y_{3}^{n}<0$

Então, $\lim g\left(v_{1}^{n}\right)=\left(x_{1}, y_{1}\right)$ tem coordenadas $x_{1} \leqslant 0$ e $y_{1} \geqslant 0, \lim g\left(v_{2}^{n}\right)=$ $\left(x_{2}, y_{2}\right)$ tem coordenadas $x_{2} \geqslant 0$ e $y_{2} \geqslant 0$ e $\lim g\left(v_{3}^{n}\right)=\left(x_{3}, y_{3}\right)$ tem ordenada $y_{3} \leqslant 0$. Como $\mathbb{T}$ é compacto e $v_{i}^{n} \in \mathbb{T}, \forall i=1,2,3, \forall n \in \mathbb{N}$, a menos de considerar subsequências, podemos supor que existe $v \in \mathbb{T}$ tal que $v_{1}^{n} \rightarrow v$, $v_{2}^{n} \rightarrow v$ e $v_{3}^{n} \rightarrow v$. Assim, $\lim g\left(v_{1}^{n}\right)=\lim g\left(v_{2}^{n}\right)=\lim g\left(v_{3}^{n}\right)=g(v)$, pois $g$ é contínua. Portanto, $g(v)=(x, y)$ tem $x=0$ e $y=0$. Logo, $v$ é ponto fixo. 


\section{4}

\section{Aplicações no ensino}

O tema desse trabalho foi discutido com um grupo de alunos do $9^{\mathrm{O}}$ ano do Ensino Fundamental de uma escola pública municipal de Rio das Ostras, no estado do Rio de Janeiro. Optamos por trabalhar com esses alunos por demonstrarem interesse em desenvolver novos conhecimentos, principalmente quando se trata de matemática. O estudo foi realizado no contra-turno, com um total de quatro encontros de duas horas e meia cada. Quando convidados para participar desse estudo, os alunos foram avisados que se tratava de um trabalho de dissertação de mestrado sobre dois interessantes lemas do matemático alemão chamado Emanuel Sperner e que esse estudo teria como base dois jogos de tabuleiro: o Jogo dos Impactos (Capítulo 2) e o Jogo de Sperner (Capítulo 3).

O Jogo dos Impactos teve como objetivo revisar conceitos como paridade e permitir a construção de conhecimentos matemáticos por meio da observação e análise de resultados, levando o aluno a formular conjecturas e procurar meios para justificá-las. O Jogo de Sperner foi abordado como aplicação do lema para segmentos e do lema para triangulações. Vale ressaltar que esse modo como utilizamos os jogos foi elaborado nessa dissertação.

\section{1}

\section{Jogo dos Impactos}

No primeiro encontro, após o conhecimento das regras do Jogo dos Impactos (ver Regra 2.4), os alunos realizaram diversas partidas, em tabuleiros com diferentes números de casas, para que pudessem perceber que o resultado do jogo independe do número de casas do tabuleiro e até mesmo do fato desse número ser par ou ímpar.

Desde o primeiro momento, os alunos se preocuparam em criar estratégias para vencer. No entanto, não conseguiram perceber padrões nos resultados que davam vitória ao primeiro (ou ao segundo) jogador. Após um tempo de análise dos jogos terminados, sem sucesso, foi sugerido que eles observassem as cores das casas dos extremos de cada tabuleiro (Figura 4.1). Assim, eles perceberam que todo jogo vencido pelo primeiro jogador tinha extremos de cores distintas e todo jogo que deu vitória ao segundo jogador tinha extremos de mesma cor. 


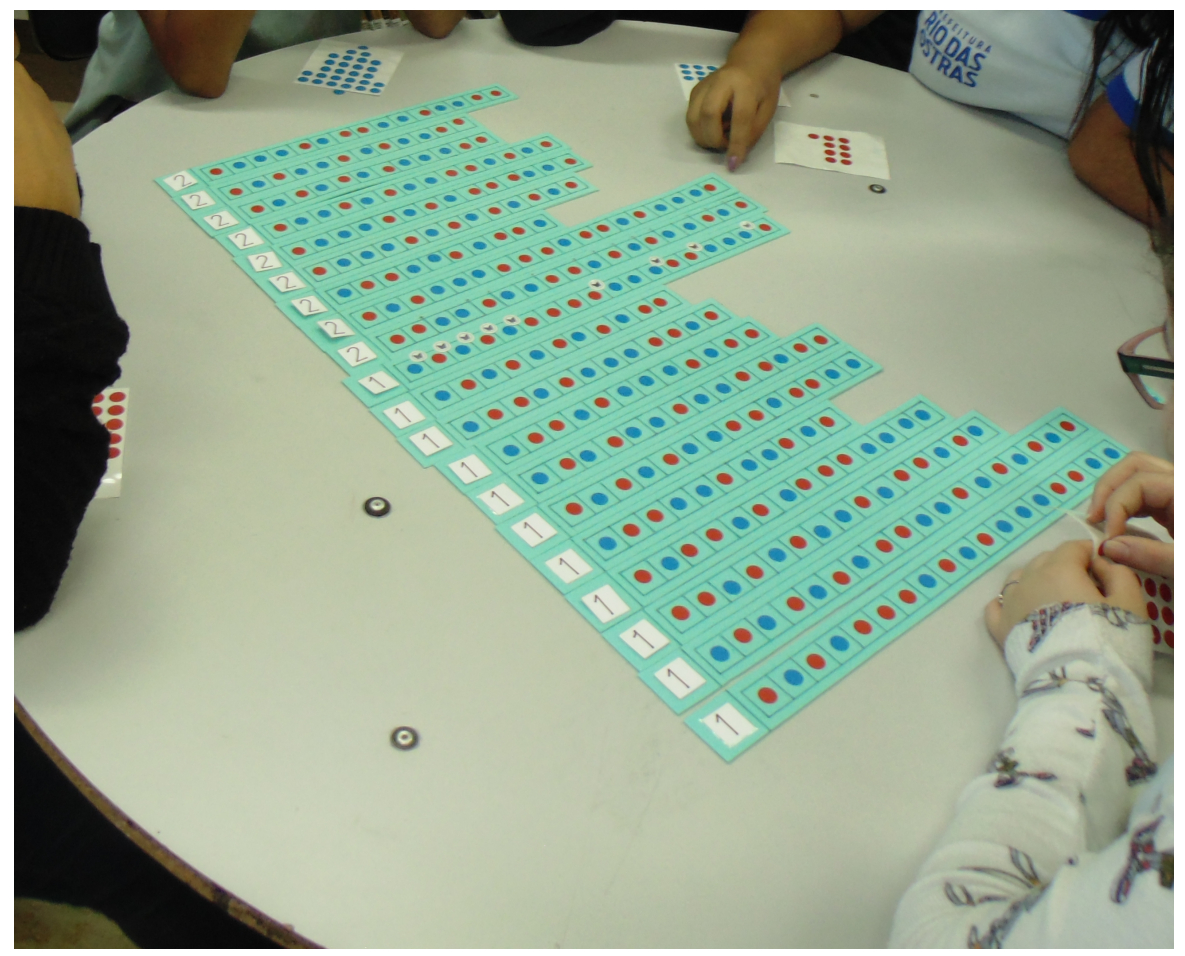

Figura 4.1: Jogo terminado. Os números indicam o jogador que venceu.

Com essa observação enunciamos o lema de Sperner para segmentos e fizemos uma prova intuitiva do fato. Antes disso, fez-se necessária uma breve revisão de adição de números pares e ímpares, para que os alunos percebessem que dados $a \in \mathbb{Z}$ e $p$ par, então $a+p$ tem mesma paridade de $a$. Nesse momento, os alunos mostraram desconhecer a forma geral de números pares $(2 k, k \in \mathbb{Z})$ e de números ímpares $(2 k+1, k \in \mathbb{Z})$, assim como as incertezas "a soma de dois pares é par?", "a soma de um par e um ímpar é ímpar?" e "a soma de dois ímpares é par?". Observamos isso com exemplos numéricos e fizemos a prova formal. Os alunos acompanharam bem a prova e ficaram entusiasmados por aprender a mostrar um fato que acreditavam ser verdadeiro, mas não tinham certeza.

A prova intuitiva do lema de Sperner foi feita da seguinte forma: o tabuleiro inicial tem apenas os extremos preenchidos com duas cores distintas. Imaginamos que o tabuleiro tem apenas essas duas casas. A seguir, acrescentamos uma casa ao tabuleiro, entre as iniciais, e a preechemos com uma cor. Repetimos o processo indutivamente, acrescentando uma casa (e uma cor) de cada vez. Os alunos perceberam que surgem dois novos impactos ou não surgem novos impactos, dependendo da cor da peça acrescentada.

Então, aplicando as ideias revisadas, os alunos puderam constatar que, em cada passo, somamos um número par de impactos a um número ímpar de impactos dados. Concluíram, assim, que o número de impactos permanece ím- 
par, independentemente das peças do meio. Feito isso, os alunos questionaram e concluíram que a análise para o caso de extremos de mesma cor é análoga. Só que nesse caso o número de impactos permanece par, já que estamos somando um número par de impactos a um número par de impactos dados.

Após esse estudo matemático, voltamos ao jogo para tentar criar estratégias para vencer, uma vez que tínhamos o conhecimento de que o primeiro jogador vence quando os extremos tem cores distintas e o segundo jogador vence quando os extremos tem cores iguais. A reação da maioria dos primeiros jogadores foi logo preencher um dos extremos para que o outro fosse preenchido pelo segundo jogador. No entanto, em alguns casos, isso não aconteceu, levando-os a perceber que essa não seria a melhor estratégia para vencer. Após poucas partidas, uma aluna chega à estratégia para o primeiro jogador ganhar: "esperar o adversário ocupar um extremo para em seguida ocupar o outro". Com isso, jogamos mais algumas partidas e comprovamos que a estratégia realmente funciona. Alguns questionaram como fazer para o segundo jogador vencer. Debatemos a questão e concluímos que não há estratégia vencedora para o segundo jogador. A partir desse momento todos queriam iniciar o jogo.

No segundo encontro, fizemos uma breve revisão do que discutimos no primeiro e seguimos com uma adaptação do Jogo dos Impactos. No jogo adaptado, o tabuleiro é circular, conforme Figura 4.2 e segue a mesma regra do jogo original.

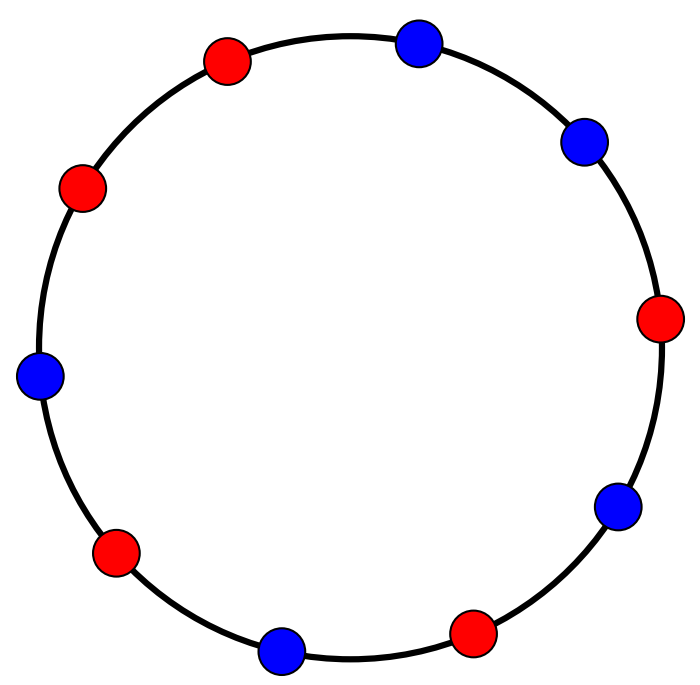

Figura 4.2: Jogo dos Impactos no círculo. O segundo jogador é azul e ganhou.

Após algumas jogadas, em tabuleiros com variados números de casas, os alunos verificaram que nesse jogo o número de impactos é sempre par. Portanto, a vitória do segundo jogador é garantida, independentemente do número de 
pontos a serem coloridos e de como esses pontos são coloridos. Os alunos foram questionados do porquê de isso acontecer sempre. Depois de algumas discussões uma das alunas sugeriu que poderíamos "abrir" o círculo e transformá-lo no tabuleiro tradicional do Jogo dos Impactos. Mas isso, segundo análise da aluna, levaria a um número par de impactos se o "corte" fosse feito entre dois pontos de mesma cor e a um número ímpar de impactos, se fosse feito entre dois pontos de cores distintas. Nesse momento, fez-se necessário intervir para que os alunos notassem que ao "abrirmos" o círculo entre dois pontos de cores distintas, no tabuleiro correspondente há um impacto a menos do que tinha no círculo e "cortando" entre pontos de mesma cor, não alteramos o número de impactos (Figura 4.3). Assim, se no tabuleiro tradicional há um número ímpar de impactos (extremos de cores distintas), no círculo há um número par e se no tabuleiro tradicional há um número par de impactos (extremos de mesma cor), no círculo também há um número par, já que não alteramos a quantidade de impactos nesse caso.

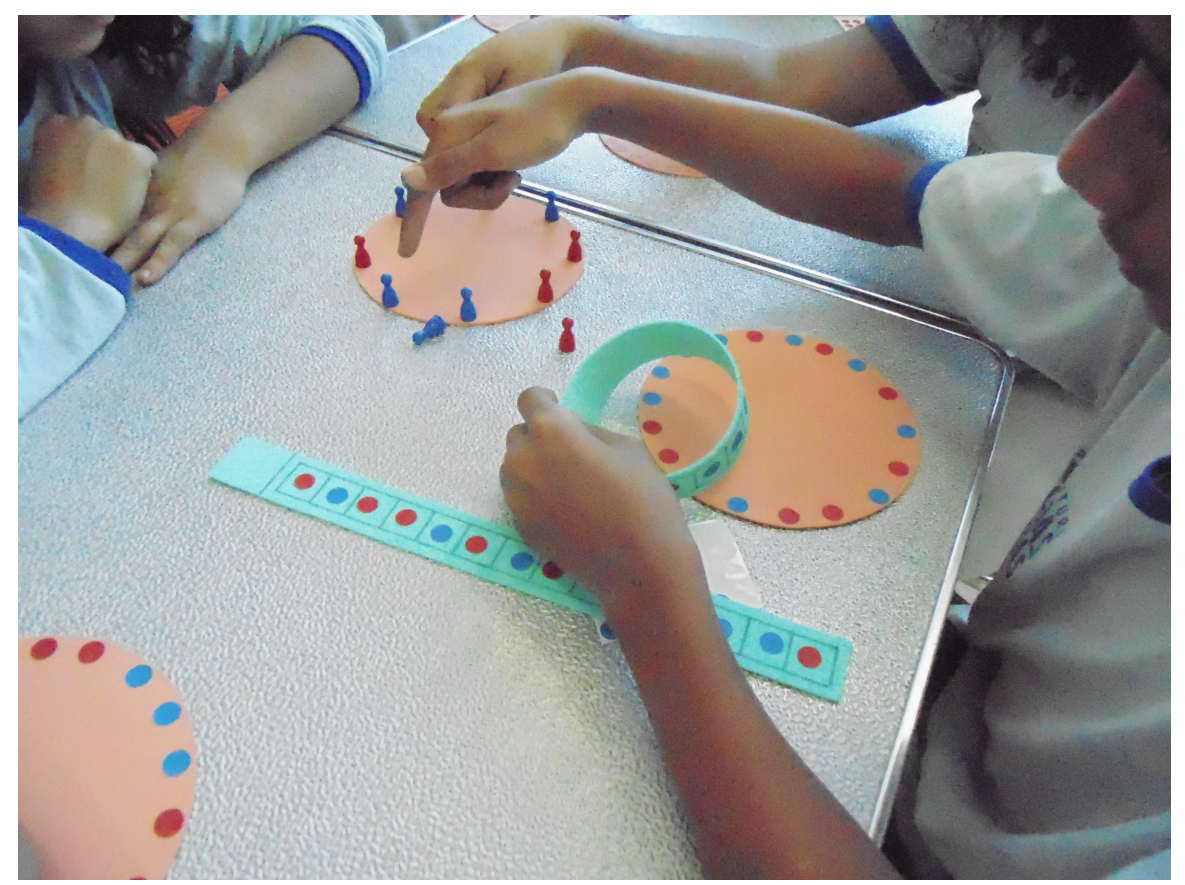

Figura 4.3: Jogo dos Impactos no círculo.

Tivemos o cuidado de não fazer o tabuleiro com a forma de coroa circular (Figura 4.4), para não sugerir aos alunos a ideia de associar esse tabuleiro ao do Jogo dos Impactos. 


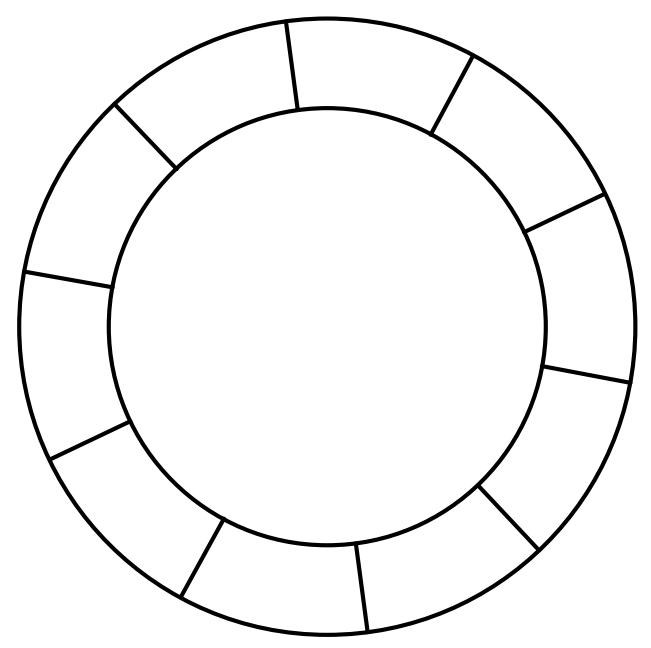

Figura 4.4: Uma "coroa circular".

\section{2}

\section{Jogo de Sperner}

Diferente do que fizemos na aplicação do Jogo dos Impactos, nesse jogo não buscamos discutir matemática a partir de seus resultados, pelo menos não no primeiro momento. Antes de trabalharmos com o jogo, definimos triangulações e triângulos completos, enunciamos o lema de Sperner para triangulações e verificamos sua veracidade.

Esse estudo foi realizado no terceiro encontro. Para isso, cada aluno recebeu uma ficha com um triângulo, cujos vértices estavam marcados com cores distintas (vermelho, azul e verde) e no qual havia uma triangulação. Foi solicitado que os alunos colorissem, aleatoriamente, os vértices da triangulação usando as cores dadas nos vértices do triângulo original e destacassem as arestas "azuis-vermelhas" e os triângulos completos assim obtidos (Figura 4.5). Em seguida, fizemos a contagem das arestas "azuis-vermelhas" do bordo do triângulo e dos triângulos completos da triangulação e verificamos que para cada triângulo essas quantidades tinham a mesma paridade. Assim, pudemos enunciar e provar o Lema de Sperner para triangulações. A prova que fizemos foi a mesma apresentada no Capítulo 3 desse trabalho (Lema 3.2).

A compreensão dessa demonstração e, principalmente, de seu resultado, por parte dos alunos foi bastante satisfatória. Eles ficaram entusiasmados ao perceber que a matemática não é apenas um conjunto de fórmulas e cálculos, como muitas vezes é apresentada, sem muita explicação do porquê funcionam. 


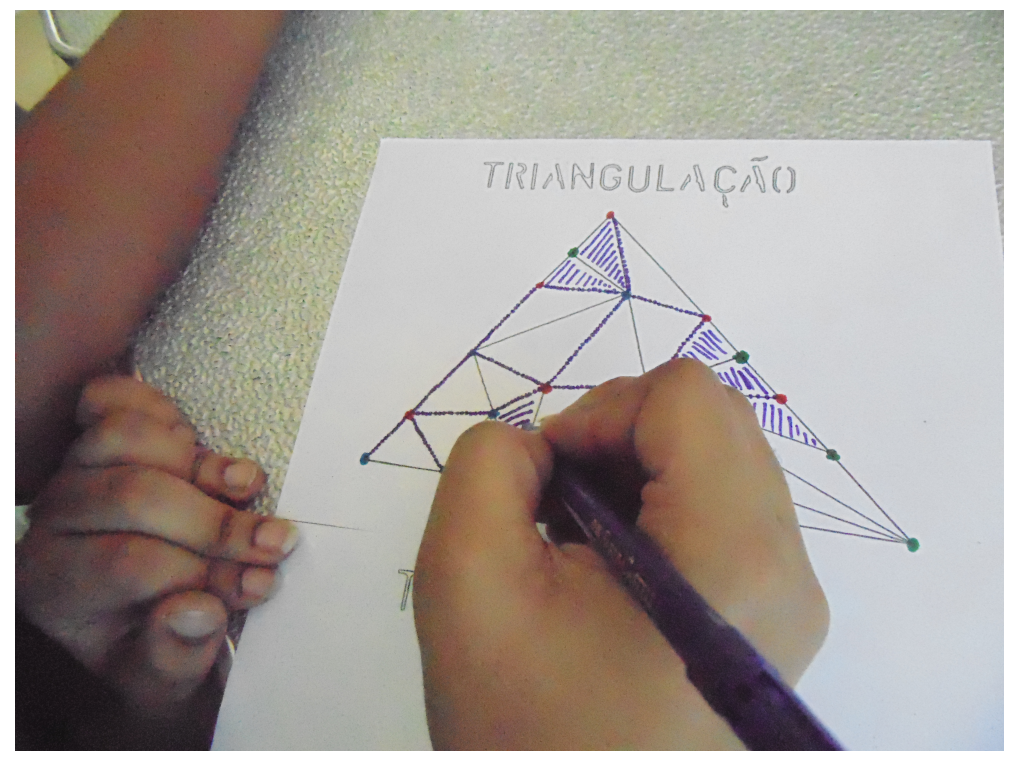

Figura 4.5: O Lema de Sperner para triangulações.

Finalmente, no quarto encontro, fomos ao Jogo de Sperner (Figura 4.6). Apresentamos sua única regra (Regra 3.4) e objetivo e jogamos algumas partidas. Os alunos perceberam que sempre haveria triângulo completo e a pergunta natural foi porque isso acontece. Algumas ideias foram discutidas até que um aluno associou o fato aos lemas estudados, apresentando a seguinte justificativa: "Como os extremos tinham cores distintas, o número de arestas "azuis-vermelhas" no bordo do triângulo é ímpar e a paridade dos triângulos completos é a mesma. Se é ímpar, não pode ser zero. Logo, existe triângulo completo."

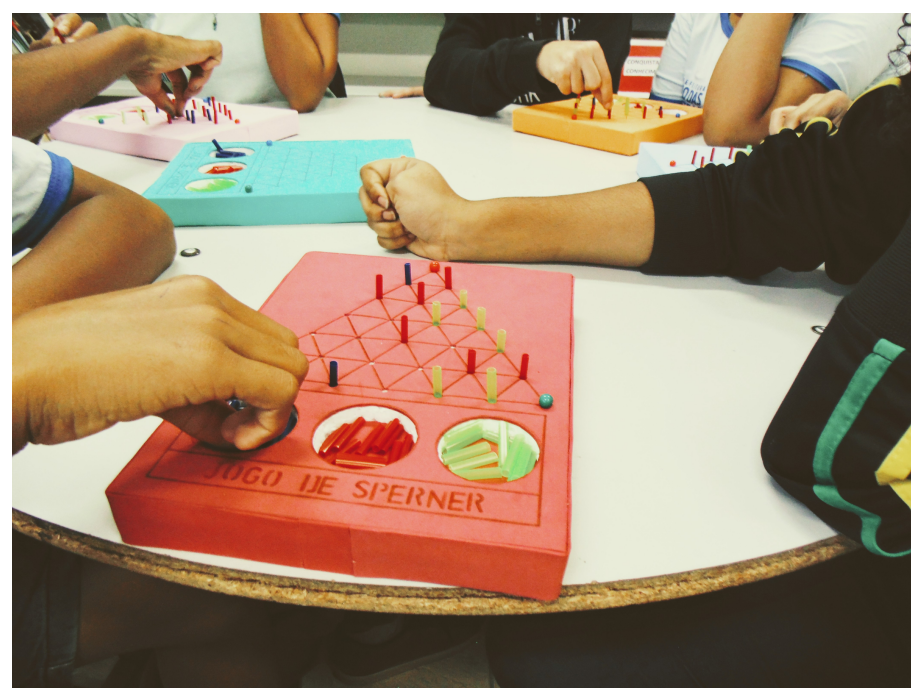

Figura 4.6: O Jogo de Sperner.

Nesse momento, alcançamos os objetivos do trabalho com esse jogo. Os 
alunos conseguiram associar e aplicar conhecimentos já adquiridos para obter ou justificar novas informações.

Mas ainda não encerramos. Os alunos sugeriram uma adaptação para esse jogo (Figura 4.7). Usar apenas duas cores nos vértices do triângulo original, mantendo a regra de sobre os lados do tabuleiro só poder usar peças das cores de seus extremo e tendo que usar peças das três cores.

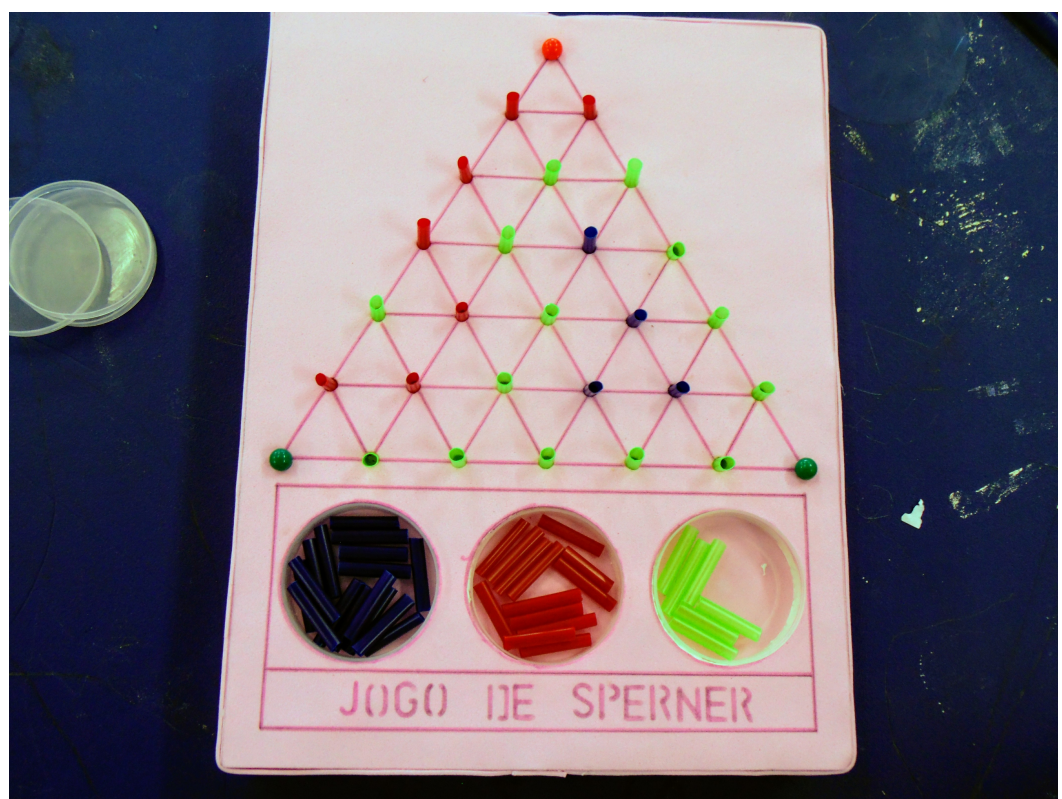

Figura 4.7: Jogo de Sperner adaptado.

Mal iniciamos a partida e um aluno fez a observação de que nesse caso poderiam não existir triângulos completos: "como dois vértices têm cores iguais dá par (par, ímpar e ímpar dá par)". A partir desse momento, o jogo se transformou em um desafio individual. Cada aluno tinha que preencher todo o tabuleiro, conforme as regras, sem formar um triângulo completo. 


\section{5}

\section{Considerações finais}

Motivados pelo problema geométrico de dividir um quadrado em triângulos de mesma área, tivemos a oportunidade de conhecer um pouco de teoria das valorações e combinatória, aplicadas ao estudo de geometria plana e de um problema de topologia. Destacamos o fabuloso método de contagem utilizado na prova do lema de Sperner para triângulações, as colorações usadas nas provas dos teoremas de Monsky e do ponto fixo de Brouwer e as valorações diádicas.

Restringimos o uso das valorações a $\mathbb{Q}$ devido à complexidade para fazer sua extensão para $\mathbb{R}$. Um estudo posterior dos pormenores dessa extensão é certamente desejável. Em particular, isso possibilitará o entendimento do caso geral do teorema de Monsky (Teorema 2.15). Além disso, temos intenção de estudar outras aplicações dos lemas de Sperner, como por exemplo a prova do teorema do ponto fixo de Brouwer para dimensão qualquer e generalizações do teorema de Monsky.

Com relação às aplicações no ensino, embora a matemática discutida com os alunos não seja trivial, o comprometimento e interesse dos mesmos possibilitaram resultados bastante satisfatórios. Certamente, o fato do estudo ser realizado com alunos que gostam de aprender, sobretudo matemática, contribuiu para os resultados alcançados. O uso dos jogos propiciou um aprendizado de forma mais leve e descontraída. Esse pode ser um bom caminho para tentarmos aplicar métodos como os descritos nesta dissertação para turmas maiores, mais heterogêneas e de outros níveis de escolaridade.

O desenvolvimento desse trabalho nos permitiu perceber o quanto a matemática pode ser interessante para os alunos, quando lhes damos a oportunidade de observar, questionar, discutir, perceber particularidade e generalidades, desenvolvendo de forma crítica o saber matemático. Além disso, percebemos como a participação do aluno é importante na construção do conhecimento. 


\section{Referências bibliográficas}

[1] SPERNER, E.. Neuer Beweis für die Invarianz der Dimensionszahl und des Gebietes. Einzelschriften; Hamburger Mathematische. H. 7. Verlag B.G. Teubner, 1928.

[2] DANTCHEV, S.. On the complexity of the sperner lemma. Lecture notes in computer science, 3988:115, 2006.

[3] THOMAS, J.. A dissection problem. Mathematics Magazine, 41(4):187190, 1968.

[4] MONSKY, P.. On dividing a square into triangles. The American Mathematical Monthly, 77(2):161-164, 1970.

[5] MEAD, D.. Dissection of the hypercube into simplexes. Proceedings of the American Mathematical Society, 76(2):302-304, 1979.

[6] PONIACHIK, J.. Jogos de sperner. Revista do Professor de Matemática, 39(1):27-30, 1999.

[7] LANG, S.. Algebra revised third edition. Graduate Texts in Mathematics, 1(211):465-499, 2002.

[8] AIGNER, M.; ZIEGLER, G. M.. One square and an odd number of triangles. Proofs from THE BOOK, p. 131-138, 2010.

[9] AZAMBujA, T. A. R. D.. Os Lemas de Sperner no Ensino Médio e uma modesta introdução à Topologia. Universidade Estadual Paulista (UNESP), 2014. 
A

\section{Prova do Lema 2.8}

A.1 A valoração diádica $|\cdot|_{2}: \mathbb{Q} \longrightarrow \mathbb{R}$ tem as seguintes propriedades:

1. $|x y|_{2}=|x|_{2}|y|_{2}$

2. $|x+y|_{2} \leqslant|x|_{2}+|y|_{2}$

3. Se $|x|_{2}<|y|_{2}$, então $|x+y|_{2}=|y|_{2}$

4. Se $|x|_{2}=|y|_{2}$, então $|x+y|_{2}<|x|_{2} e|x+y|_{2}<|y|_{2}$

Demonstração.

1. $|x y|_{2}=|x|_{2}|y|_{2}$ :

Sejam $x=2^{n} \frac{a}{b}$ e $y=2^{m} \frac{p}{q}$, com $a, b, p$ e $q$ ímpares. Temos que $x y=2^{n} \frac{a}{b} 2^{m} \frac{p}{q}=2^{n+m} \frac{a p}{b q}$, com $a p$ e $b q$ ímpares. Então

$$
|x y|_{2}=\left(\frac{1}{2}\right)^{n+m}=\left(\frac{1}{2}\right)^{n}\left(\frac{1}{2}\right)^{m}=|x|_{2}|y|_{2} .
$$

Portanto, $|x y|_{2}=|x|_{2}|y|_{2}$.

2. $|x+y|_{2} \leqslant|x|_{2}+|y|_{2}$ :

Sejam $x=2^{n} \frac{a}{b}$ e $y=2^{m} \frac{p}{q}$, com $a, b, p$ e $q$ ímpares. Supondo, sem perda de generalidade, que $n \geqslant m$, temos

$$
x+y=2^{n} \frac{a}{b}+2^{m} \frac{p}{q}=\frac{2^{n} a q+2^{m} p b}{b q}=2^{m}\left(\frac{2^{n-m} a q+p b}{b q}\right),
$$

com $\left(2^{n-m} a q+p b\right)$ e $b q$ ímpares. Assim,

$$
|x+y|_{2}=\left(\frac{1}{2}\right)^{m} \leqslant\left(\frac{1}{2}\right)^{m}+\left(\frac{1}{2}\right)^{n}=|y|_{2}+|x|_{2}=|x|_{2}+|y|_{2} .
$$

Logo, $|x+y|_{2} \leqslant|x|_{2}+|y|_{2}$.

3. $|x|_{2}<|y|_{2} \Longrightarrow|x+y|_{2}=|y|_{2}$ :

Sejam $x=2^{n} \frac{a}{b}$ e $y=2^{m} \frac{p}{q}$, com $a, b, p$ e $q$ ímpares. Temos que

$$
|x|_{2}<|y|_{2} \Longleftrightarrow\left(\frac{1}{2}\right)^{n}<\left(\frac{1}{2}\right)^{m} \Longleftrightarrow n>m .
$$


Assim,

$$
|x+y|_{2}=\left|2^{m}\left(\frac{2^{n-m} a q+p b}{b q}\right)\right|_{2}=\left(\frac{1}{2}\right)^{m}=|y|_{2} .
$$

Portanto, $|x|_{2}<|y|_{2} \Longrightarrow|x+y|_{2}=|y|_{2}$

4. $|x|_{2}=|y|_{2} \Longrightarrow|x+y|_{2}<|x|_{2}$ e $|x+y|_{2}<|y|_{2}$ :

Sejam $x=2^{n} \frac{a}{b}$ e $y=2^{m} \frac{p}{q}$, com $a, b, p$ e $q$ ímpares. Temos que:

(a) $|x|_{2}=|y|_{2} \Longleftrightarrow\left(\frac{1}{2}\right)^{n}=\left(\frac{1}{2}\right)^{m} \Longleftrightarrow n=m \Longrightarrow n-m=0$.

(b) $x+y=2^{m}\left(\frac{2^{n-m} a q+p b}{b q}\right)=2^{m}\left(\frac{a q+p b}{b q}\right)$, pois $n-m=0$.

Como $p b$ e $a q$ são ímpares temos que $(p b+a q)$ é par e, portanto, tem algum fator 2, digamos $2^{k}$, em sua decomposição em primos. Assim, $x+y=2^{m+k}\left(\frac{p^{\prime}}{q^{\prime}}\right)$, com $p^{\prime}$ e $q^{\prime}$ ímpares. Então,

$$
|x+y|_{2}=\left(\frac{1}{2}\right)^{m+k}<\left(\frac{1}{2}\right)^{m}=|x|_{2}=|y|_{2} .
$$

Portanto, $|x|_{2}=|y|_{2} \Longrightarrow|x+y|_{2}<|x|_{2}$ e $|x+y|_{2}<|y|_{2}$. 
B

\section{Prova do Lema 2.10}

B.1 $Q_{2}$ e $Q_{3}$ são invariantes por translação de pontos de $Q_{1}$, isto é:

1. $\left(x_{1}, y_{1}\right) \in Q_{1} e\left(x_{2}, y_{2}\right) \in Q_{2} \Longrightarrow\left(x_{1}+x_{2}, y_{1}+y_{2}\right) \in Q_{2}$

2. $\left(x_{1}, y_{1}\right) \in Q_{1}$ e $\left(x_{3}, y_{3}\right) \in Q_{3} \Longrightarrow\left(x_{1}+x_{3}, y_{1}+y_{3}\right) \in Q_{3}$

Demonstração. Para mostrar que $\left(x_{1}+x_{2}, y_{1}+y_{2}\right) \in Q_{2}$ e $\left(x_{1}+x_{3}, y_{1}+y_{3}\right) \in Q_{3}$, devemos mostrar que $\left|x_{1}+x_{2}\right|_{2} \geqslant 1,\left|y_{1}+y_{3}\right|_{2} \geqslant 1,\left|x_{1}+x_{2}\right|_{2} \geqslant\left|y_{1}+y_{2}\right|_{2} \mathrm{e}$ $\left|x_{1}+x_{3}\right|_{2}<\left|y_{1}+y_{3}\right|_{2}$. Usaremos o tempo todo o Lema 2.8 .

1. $\left|x_{1}+x_{2}\right|_{2} \geqslant 1$

Se $\left(x_{1}, y_{1}\right) \in Q_{1}$ e $\left(x_{2}, y_{2}\right) \in Q_{2}$, por definição $\left|x_{1}\right|_{2}<1$ e $\left|x_{2}\right|_{2} \geqslant 1$. Logo, $\left|x_{1}\right|_{2}<\left|x_{2}\right|_{2}$. Pela propriedade 3 do Lema 2.8, se $\left|x_{1}\right|_{2}<\left|x_{2}\right|_{2}$ então $\left|x_{1}+x_{2}\right|_{2}=\left|x_{2}\right|_{2}$. Além disso, $\left|x_{2}\right|_{2} \geqslant 1$. Então, $\left|x_{1}+x_{2}\right|_{2} \geqslant 1$.

2. $\left|y_{1}+y_{3}\right|_{2} \geqslant 1$

Se $\left(x_{1}, y_{1}\right) \in Q_{1}$ e $\left(x_{3}, y_{3}\right) \in Q_{3}$ então $\left|y_{1}\right|_{2}<1$ e $\left|y_{3}\right|_{2} \geqslant 1$. Assim, $\left|y_{1}\right|_{2}<$ $\left|y_{3}\right|_{2}$ e novamente pela propriedade 3 do Lema 2.8, $\left|y_{1}+y_{3}\right|_{2}=\left|y_{3}\right|_{2}$. Além disso, por definição, $\left|y_{3}\right|_{2} \geqslant 1$. Então, $\left|y_{1}+y_{3}\right|_{2} \geqslant 1$.

3. $\left|x_{1}+x_{2}\right|_{2} \geqslant\left|y_{1}+y_{2}\right|_{2}$

Vamos mostrar que $\left|x_{1}+x_{2}\right|_{2} \geqslant\left|y_{1}+y_{2}\right|_{2}$, analisando dois casos:

(a) $\left|y_{2}\right|_{2} \geqslant 1$

Se $\left(x_{1}, y_{1}\right) \in Q_{1}$ e $\left(x_{2}, y_{2}\right) \in Q_{2}$, por definição $\left|x_{1}\right|_{2}<1,\left|x_{2}\right|_{2} \geqslant 1$ e $\left|y_{1}\right|_{2}<1$ e, pela restrição desse caso, $\left|y_{2}\right|_{2} \geqslant 1$. Então $\left|x_{1}\right|_{2}<$ $\left|x_{2}\right|_{2}$ e $\left|y_{1}\right|_{2}<\left|y_{2}\right|_{2}$ e mais uma vez temos $\left|x_{1}+x_{2}\right|_{2}=\left|x_{2}\right|_{2}$ e $\left|y_{1}+y_{2}\right|_{2}=\left|y_{2}\right|_{2}$. Além disso, $\left|x_{2}\right|_{2} \geqslant\left|y_{2}\right|_{2}$, pois $\left(x_{2}, y_{2}\right) \in Q_{2}$. Portanto, $\left|x_{1}+x_{2}\right|_{2} \geqslant\left|y_{1}+y_{2}\right|_{2}$.

(b) $\left|y_{2}\right|_{2}<1$

Pela definição de $Q_{1},\left|y_{1}\right|_{2}<1$ e, pela restrição desse caso $\left|y_{2}\right|_{2}<1$. Assim, $\max \left\{\left|y_{1}\right|_{2},\left|y_{2}\right|_{2}\right\}<1$. Como $\left|y_{1}+y_{2}\right|_{2} \leqslant \max \left\{\left|y_{1}\right|_{2},\left|y_{2}\right|_{2}\right\}$, temos que $\left|y_{1}+y_{2}\right|_{2}<1$. Além disso, novamente $\left|x_{1}+x_{2}\right|_{2}=\left|x_{2}\right|_{2}$, pois $\left|x_{1}\right|_{2}<\left|x_{2}\right|_{2}$ e, pela definição de $Q_{2},\left|x_{2}\right|_{2} \geqslant 1$. Então 


$$
\begin{aligned}
& \left|x_{1}+x_{2}\right|_{2} \geqslant 1 . \text { Daí, }\left|y_{1}+y_{2}\right|_{2}<1 \text { e }\left|x_{1}+x_{2}\right|_{2} \geqslant 1 . \text { Portanto, } \\
& \left|x_{1}+x_{2}\right|_{2} \geqslant\left|y_{1}+y_{2}\right|_{2} .
\end{aligned}
$$

4. $\left|x_{1}+x_{3}\right|_{2}<\left|y_{1}+y_{3}\right|_{2}$

Vamos mostrar que $\left|x_{1}+x_{3}\right|_{2}<\left|y_{1}+y_{3}\right|_{2}$, analisando dois casos:

(a) $\left|x_{3}\right|_{2} \geqslant 1$

Se $\left(x_{1}, y_{1}\right) \in Q_{1}$ e $\left(x_{3}, y_{3}\right) \in Q_{3}$, por definição $\left|x_{1}\right|_{2}<1,\left|y_{1}\right|_{2}<1$ e $\left|y_{3}\right|_{2} \geqslant 1$ e, pela restrição desse caso, $\left|x_{3}\right|_{2} \geqslant 1$. Então, $\left|x_{1}\right|_{2}<\left|x_{3}\right|_{2}$ e $\left|y_{1}\right|_{2}<\left|y_{3}\right|_{2}$ e, pela propriedade 3 do Lema 2.8, $\left|x_{1}+x_{3}\right|_{2}=\left|x_{3}\right|_{2}$ e $\left|y_{1}+y_{3}\right|_{2}=\left|y_{3}\right|_{2}$. Além disso, $\left|x_{3}\right|_{2}<\left|y_{3}\right|_{2}$, pois $\left(x_{3}, y_{3}\right) \in Q_{3}$. Portanto, $\left|x_{1}+x_{3}\right|_{2}<\left|y_{1}+y_{3}\right|_{2}$.

(b) $\left|x_{3}\right|_{2}<1$.

Pela definição de $Q_{1},\left|x_{1}\right|_{2}<1$ e, pela restrição desse caso, $\left|x_{3}\right|_{2}<1$. Então, $\max \left\{\left|x_{1}\right|_{2},\left|x_{3}\right|_{2}\right\}<1$. Pelo Corolário 2.9, $\left|x_{1}+x_{3}\right|_{2} \leqslant$ $\max \left\{\left|x_{1}\right|_{2},\left|x_{3}\right|_{2}\right\}$. Então, $\left|x_{1}+x_{3}\right|_{2}<1$. Além disso, $\left|y_{1}+y_{3}\right|_{2}=\left|y_{3}\right|_{2}$ e $\left|y_{3}\right|_{2} \geqslant 1$. Então, $\left|y_{1}+y_{3}\right|_{2} \geqslant 1$ e portanto $\left|x_{1}+x_{3}\right|_{2}<\left|y_{1}+y_{3}\right|_{2}$. 